\title{
Lycium barbarum Polysaccharides Promote Maturity of Murine Dendritic Cells through Toll-Like Receptor 4-Erk1/2-Blimp1 Signaling Pathway
}

\author{
Xiangguo Duan, ${ }^{1,2,3}$ Yaru Lan, ${ }^{4,5}$ Xiaoyu Zhang, ${ }^{4}$ Shaozhang Hou, ${ }^{3,4}$ Jian Chen, ${ }^{6}$ Bin $\mathrm{Ma}^{7}$ \\ Yuhan Xia, ${ }^{8}$ and Chunxia Su $\mathbb{D}^{3,4}$ \\ ${ }^{1}$ Department of Laboratory Medicine, College of Clinical Medicine, Ningxia Medical University, Yinchuan 750004, China \\ ${ }^{2}$ Department of Laboratory Surgery, General Hospital of Ningxia Medical University, Yinchuan 750004, China \\ ${ }^{3}$ Ningxia Innovation Team of the Foundation and Clinical Researches of Diabetes and Its Complications, Yinchuan 750004, China \\ ${ }^{4}$ School of Basic Medical Sciences, Ningxia Medical University, Yinchuan 750004, China \\ ${ }^{5}$ The People's Hospital of Caoxian, Heze 274400, China \\ ${ }^{6}$ Guolong Hospital, Yinchuan 750004, China \\ ${ }^{7}$ Department of Oncology Surgery, The First People's Hospital of Yinchuan, Yinchuan 750004, China \\ ${ }^{8}$ General Hospital of Ningxia Medical University, Yinchuan 750004, China
}

Correspondence should be addressed to Chunxia Su; chunxiasu@aliyun.com

Received 4 July 2020; Revised 11 October 2020; Accepted 30 October 2020; Published 2 December 2020

Academic Editor: Samanta Taurone

Copyright ( 2020 Xiangguo Duan et al. This is an open access article distributed under the Creative Commons Attribution License, which permits unrestricted use, distribution, and reproduction in any medium, provided the original work is properly cited.

\begin{abstract}
In previous studies, Lycium barbarum polysaccharides (LBP), a traditional Chinese medicine, can promote immature dendritic cells (DCs) to mature. However, the molecular mechanisms by which LBP works are not yet elucidated. Here, we found that LBP can induce DCs maturation, which is mainly characterized by the upregulation of MHCII and costimulatory molecules (CD80, CD86), and increase the production of IL-6 and IL-4. Furthermore, we found that LBP could increase the mRNA and protein expression of TLR4, p38, Erk1/2, JNK, and Blimp1 signal molecules. More interestingly, after blocking by Toll-like receptor 4 inhibitor, Resatorvid (TAK 242), the mRNA and protein expression of TLR4, Erk1/2, and Blimp1 was significantly decreased while the expression of p38 and JNK has not changed. Then, we found that after blocking by p38 inhibitor (SB203580), Erk inhibitor (PD98059), and JNK inhibitor (SP603580) separately, Blimp1 protein expression was significantly reduced; after downregulating Blimp1 by Blimp1-siRNA, the production of IL-6 was reduced. In conclusion, our results indicate that LBP can induce maturation of DCs through the TLR4-Erk1/2-Blimp1 signal pathway instead of the JNK/p38-Blimp1 pathway. Our findings may provide a novel evidence for understanding the molecular mechanisms of LBP on activating murine DCs.
\end{abstract}

\section{Introduction}

Chinese herbal medicine has a long history used to treat many kinds of human diseases. Lycium barbarum polysaccharides (LBP) are the major biological active ingredient of Lanthanum which consist of six kinds of monosaccharides such as arabinose, glucose, galactose, mannose, xylose, and rhamnose and have a variety of biological and pharmacological functions, including antioxidant, anticancer and antiradiation activities [1-4]. From immunology aspect, what we understood about
LBP is that it mainly regulated the functions of T cells, CTL cells, NK cells, peritoneal macrophages, and partially dendritic cells (DCs). Some studies have shown that LBP can increase the expression of surface molecular CD11c and MHCII and the secretion of IL-12p40 in mouse bone marrow-derived dendritic cells (BMDCs) [5]. However, the molecular mechanisms by which LBP works are not yet elucidated.

DCs are the most powerful antigen presenting cells (APC) known to act as a bridge between innate and adaptive immune responses [6]. Immature DCs have a strong ability 
to swallow antigens, while mature DCs have a strong capacity to present antigens. A variety of stimulus can mature DCs by binding to its cell surface receptors, which are characterized by high expression of CD40, CD80, CD86, and MHCII molecules [7]. Mature DCs are important modulators of immune response, and they are the key modulator in inducing several $\mathrm{CD} 4^{+}$effector $\mathrm{T}$ cell subsets by high secretion of cytokines. DCs can provide T cell signals as antigenic peptide, costimulatory molecules, and cytokines, thereby activate the initial $\mathrm{T}$ cell differentiation, and participate in the immune response $[8,9]$. IL-6 is a key cytokine secreted by mature DCs that can effectively induce differentiation of $\mathrm{T}$ follicular helper (Tfh) cell [10-13]. Tfh cells are able to promote humoral immune response by helping $\mathrm{B}$ cells to differentiate into plasma cells, which can produce high-affinity antibodies [14-16].

Numerous studies have shown that B lymphocyteinduced mature protein 1 (Blimp1) encoded by $\operatorname{Prdm} 1$ is the main molecule for $\mathrm{B}$ cells to differentiate into plasma cells and $\mathrm{CD}^{+} \mathrm{T}$ cells to secrete cytokines [17]. Meanwhile, Blimp1 is also involved in lipopolysaccharide- (LPS-) induced primary B lymphocyte activation, macrophage differentiation, and DC maturation $[18,19]$. Although Blimp1 is rarely expressed in bone marrow-derived DCs, it still plays a crucial role in the tolerogenic function of DCs. Reducing the expression of Blimp1 in DCs can lead to abnormal activation of the adaptive immune response, which may participate into DC differentiation and maturation [20-22].

Up to now, TLR2/4 is proposed to be a possible receptor for polysaccharides. Japanese scholars first reported that safflower polysaccharide can activate the transcription factor $\mathrm{NF} \kappa \mathrm{B}$ signal pathway through TLR4 [23]. Following that, a lot of research has also shown that many plant polysaccharides can activate the TLR4-MAPK signaling pathway in cells and improve the production of TNF- $\alpha$, IL-12, and IL-1 $\beta[24,25]$. However, there is currently no clear evidence of whether LBP are involved in the TLR-MAPK signaling pathway. In this study, we are interested to look at how LBP works to regulate the maturation of DCs and what is the molecular mechanisms of LBP on activating murine DCs.

\section{Materials and Methods}

2.1. Mice. C57BL/6 mice (SCXK-(jing) 2016-0006) were purchased from the Laboratory Animal Center of Ningxia Medical University (Yinchuan, Ningxia, China). All mice were housed in the Animal Experiment Center of Ningxia Medical University. All mouse procedures were approved by the Institutional Animal Care and Use Committee of the Ningxia Medical University.

2.2. Materials. LBP was purchased Shanxi Ciyuan Biotechnology (No.CY190218). Fetal bovine serum was purchased from PNA, Paisley, UK. Recombinant Murine GM-CSF and recombinant Murine IL-4 were both from PeproTech (USA). Lipopolysaccharide was from Solarbio, China.

2.3. Generation of DCs from Bone Marrow. Immature DCs were generated from the bone marrow using a protocol slightly modified from a previous study [5]. The cells were resuspended in complete medium containing $20 \mathrm{ng} / \mathrm{mL}$ GM-CSF and $10 \mathrm{ng} / \mathrm{mL}$ IL-4. The medium was disposed of half by the next day. Nonadherent cells were collected after 7 days of cultivation. DCs were treated with various concentrations of $\operatorname{LBP}(0,50,100$, and $200 \mu \mathrm{g} / \mathrm{mL})$ for $30 \mathrm{~min}$. In the positive control, $10 \mathrm{ng} / \mathrm{mL}$ LPS was added. In inhibition experiments, DCs pretreated with $10 \mu \mathrm{M}$ Resatorvid (TAK 242) (MCE, USA), $2.5 \mu \mathrm{M}$ BAY 11-7082 (Ab Mole, USA), $5 \mu \mathrm{M}$ SB203580 (Ab Mole, USA), $10 \mu \mathrm{M}$ PD98059 (Ab Mole, USA), $50 \mu \mathrm{M}$ SP600125 (Ab Mole, USA) for $1 \mathrm{~h}$ were treated with LBP $(200 \mu \mathrm{g} / \mathrm{mL})$ or LPS $(100 \mathrm{ng} / \mathrm{mL})$ for $30 \mathrm{~min}$.

2.4. DCs Phenotypic Characterization by Flow Cytometry (FCM). DCs were seeded in 6-well plates at $1 \times 10^{6}$ per well and incubated for $24 \mathrm{~h}$ with $\operatorname{LBP}(0,50,100$, and $200 \mu \mathrm{g} / \mathrm{mL})$ and LPS (100 ng/mL). DCs were collected and stained with PE-Cy7-conjugated CD11c, V500-conjugated MHCII, BV421-conjugated CD86, and Percp-Cy ${ }^{\mathrm{TM}}$ 5.5-conjugated CD80 (BD Bioscience, USA). Stained cells were analyzed by FCM and displayed as mean fluorescence intensity (MFI), and the higher MFI means higher expression of detected molecules.

2.5. Cytokine Examination Assay. On day 7, DCs were seeded in 6-well plates at $1 \times 10^{6}$ per well and incubated for $24 \mathrm{~h}$ with LBP $(0,50,100$, and $200 \mu \mathrm{g} / \mathrm{mL})$ and LPS $(100 \mathrm{ng} / \mathrm{mL})$. DC culture supernatants were collected to test the various cytokines by a sandwich enzyme-linked immunosorbent assay (ELISA) kit (BD Bioscience, USA) according to the manufacturer's instructions.

2.6. Taqman-PCR Assay. On day 7, DCs were coincubated with $\operatorname{LBP}(0,50,100$, and $200 \mu \mathrm{g} / \mathrm{mL})$ for $30 \mathrm{~min}$, and then, the RNA was extracted using Tiangen RNA Extraction Kit and then reverse-transcribed into cDNA using $1 \mu \mathrm{g}$ RNA. The cDNA was stored at $-80^{\circ} \mathrm{C}$ for later use. PCR was performed in a 2720 Thermal Cycler (Gene Co. Ltd.). The mRNA levels of TLR4, JNK, p38, Erk1, Erk2, and Blimp1 were normalized versus those of $\beta$-actin.

2.7. Western Blotting Assay. 25 micrograms of total protein was electrophoresed by $8 \%$ SDS PAGE. The transferred membrane was blocked in $5 \%$ nonfat milk for $1.5 \mathrm{~h}$, and then, the primary antibody was incubated at $4^{\circ} \mathrm{C}$ overnight. The secondary antibody labeled with horseradish peroxidase was detected using an ECL kit. Images were then analyzed by Image 6.0 software. $\beta$-Actin was used as a control.

2.8. RNA Silencing Assay. For RNA silencing experiments, small interfering RNA of Prdm1 (siRNA) was purchased from QIAGEN (Germany) and transfected into DCs using HiPerFect Transfection Reagent (Germany). The effect of knockdown was checked by Western blot and ELISA ( $24 \mathrm{~h}$ after transfection).

2.9. DC Stimulation with LBP In Vivo. Both $\operatorname{LBP}(0,10,20$, $40 \mathrm{mg} / \mathrm{kg}$ ) and LPS (1 mg/kg) were administered intraperitoneally to C57BL/6 mice in three groups. After 7 days, DCs were isolated from the spleen and detected for TLR4, Erk1/2, and Blimp1 expression by Western blot. 

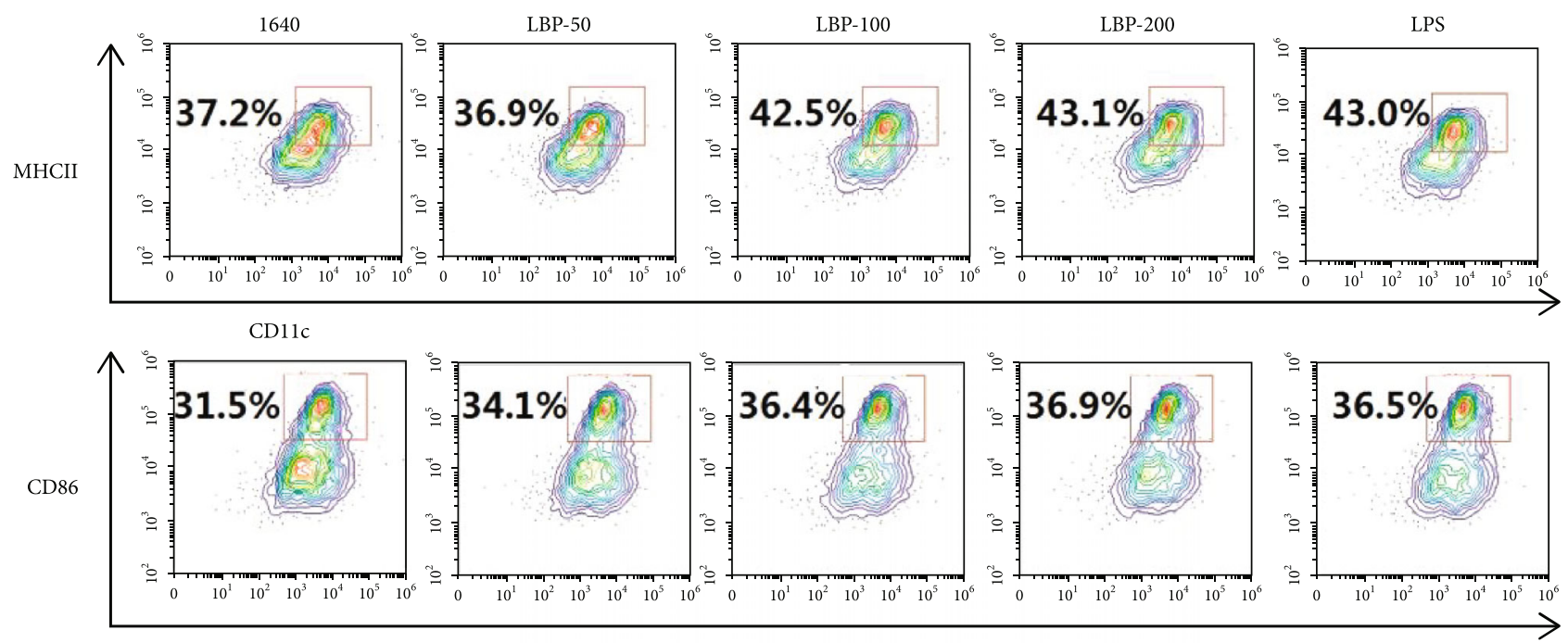

CD11c
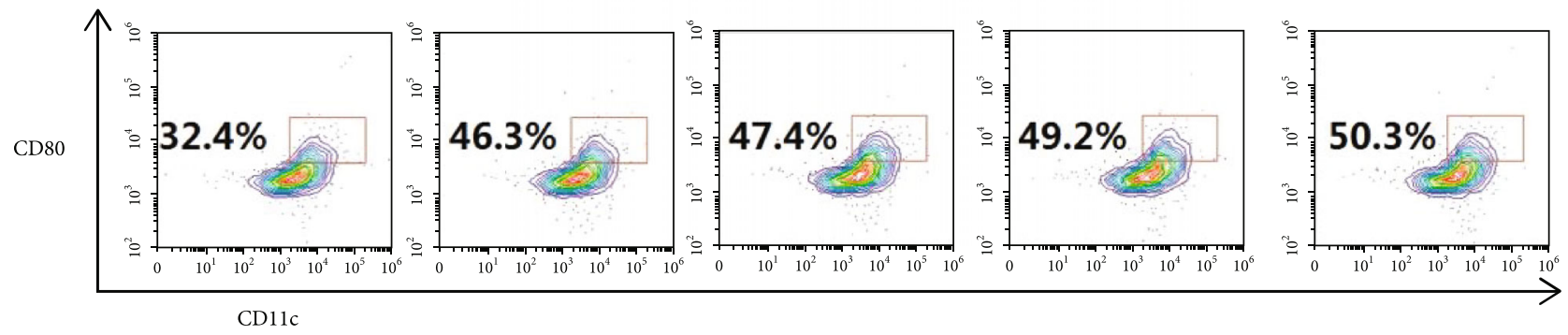

(a)

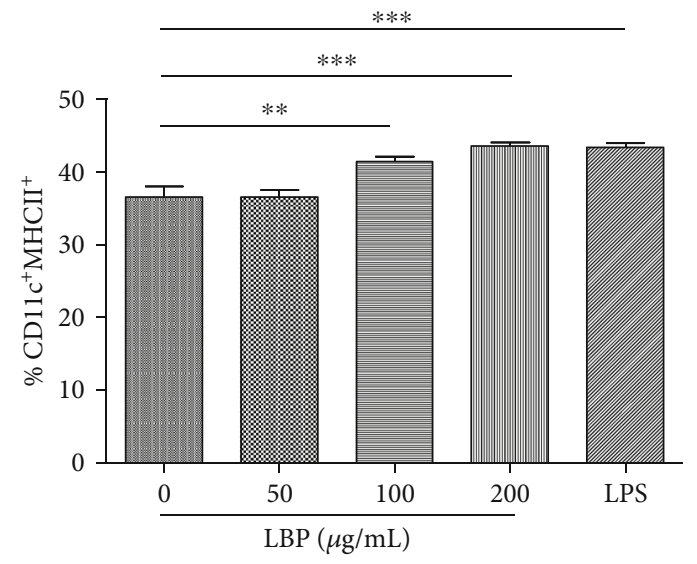

(b)

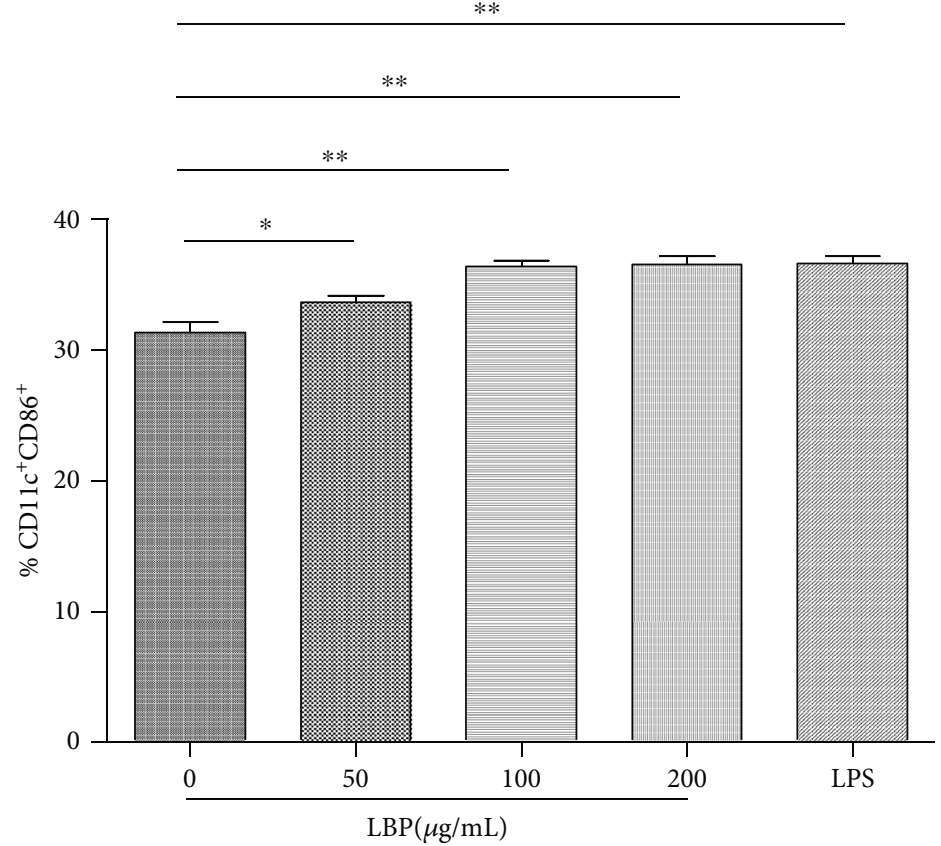

(c)

FIgURE 1: Continued. 


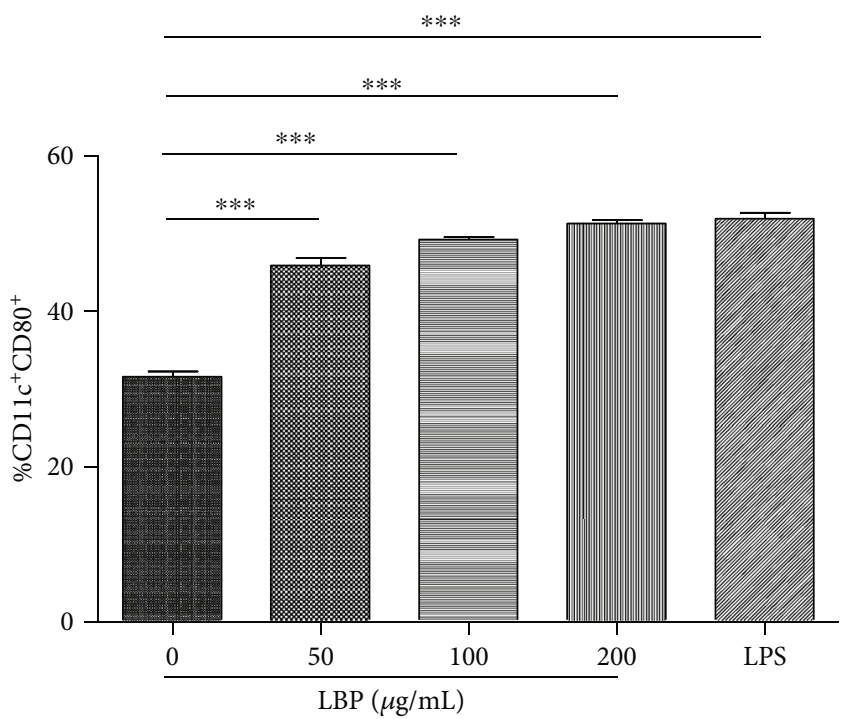

(d)

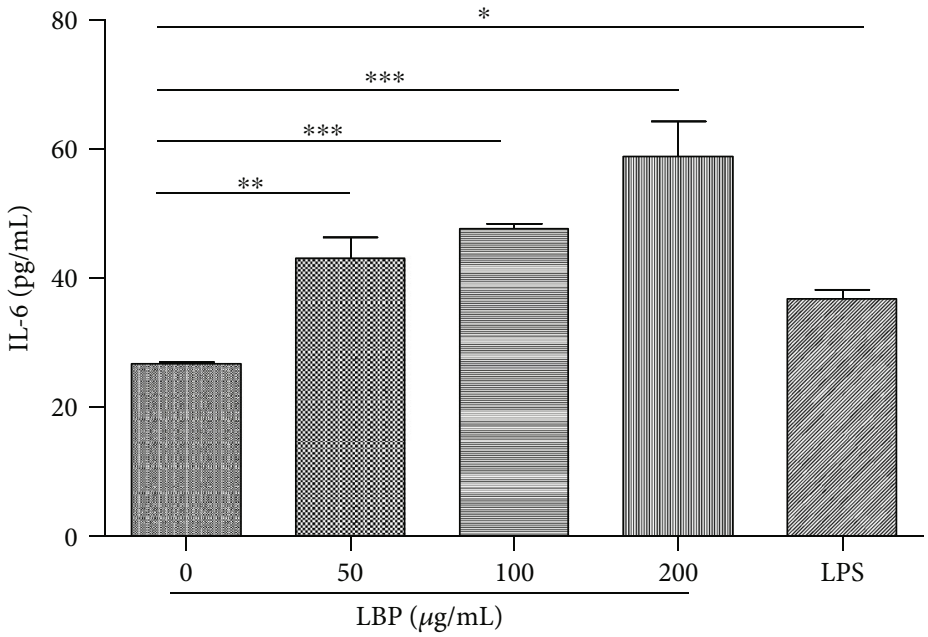

(e)

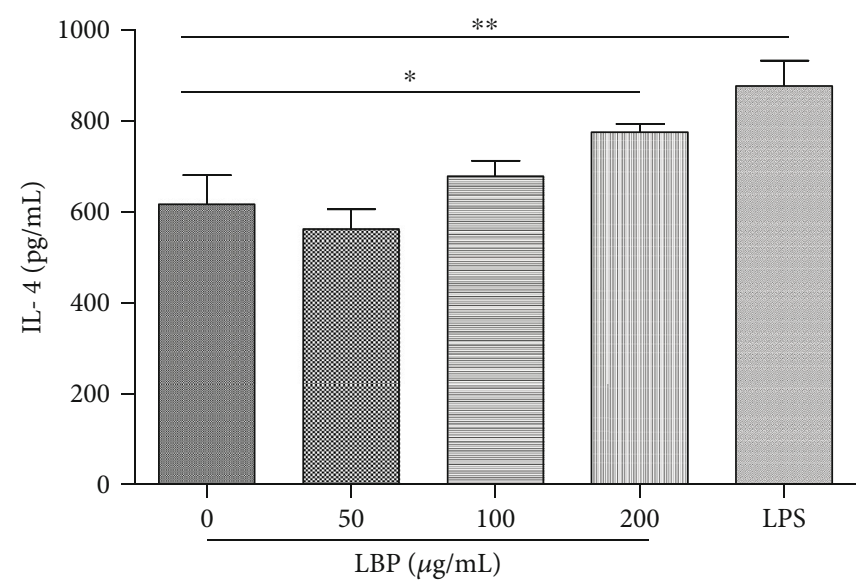

(f)

FIGURE 1: Phenotypic and functional change of DCs after treatment by LBP. After being cocultured with DCs for $24 \mathrm{~h}$ with LBP $(0,50,100$,

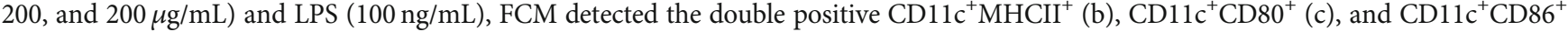
(d) cells in five groups. Supernatants were measured using ELISA kits for IL-6 (e) and IL-4 (f). Values are the mean and SD of 3 independent experiments. ${ }^{*} P<0.05,{ }^{* *} P<0.01$, and ${ }^{* * *} P<0.001$. 


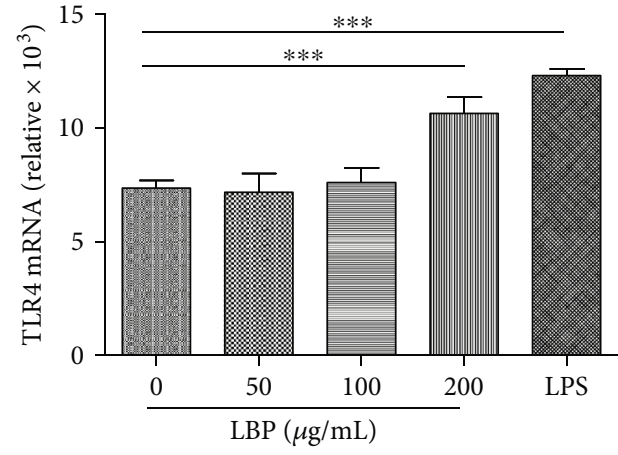

(a)

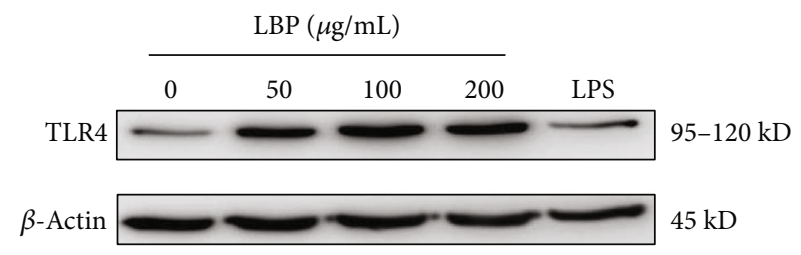

(b)

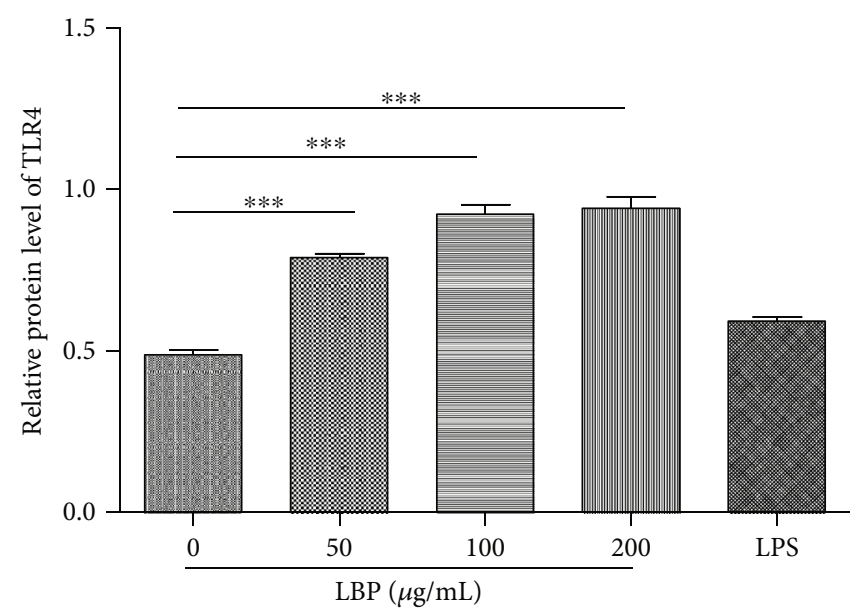

(c)

FIGURE 2: LBP improve TLR4 expression on the cell surface of DCs. DCs were stimulated for 30 min with LBP $(0,50,100$, and 200 $\mu \mathrm{g} / \mathrm{mL})$ and LPS $(100 \mathrm{ng} / \mathrm{mL})$, respectively. After stimulation, the cell RNA and protein were extracted; gene and protein expression of TLR4 was detected by Taqman-PCR (a) and Western blot (b) and (c) separately. Values are the mean and SD of 3 independent experiments. ${ }^{*} P<0.05$, ${ }^{* *} P<0.01$, and ${ }^{* * *} P<0.001$ were considered statistically significant different from control.

2.10. Statistical Analysis. Statistical analysis was performed using Prism 5.0 (GraphPad). Measurement data were shown as the mean \pm SD. Statistical significance was calculated by one-way analysis of variant: $P<0.05$ was considered the statistical significance.

\section{Results}

3.1. Phenotypic and Functional Change of DCs after Treatment by LBP. To investigate the potential role of LBP in DCs maturity, we started by analyzing the changes of DCs surface molecular after LBP treatment. After $24 \mathrm{~h}$ poststimulation, the expression of the DC surface markers MHCII, CD86, and CD80 were detected by FCM. First,

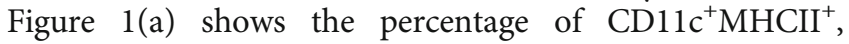
$\mathrm{CD} 11 \mathrm{c}^{+} \mathrm{CD} 86^{+}$, and $\mathrm{CD} 11 \mathrm{c}^{+} \mathrm{CD} 80^{+}$cells in different experimental groups, and Figures $1(\mathrm{~b})-1(\mathrm{~d})$ show the statistical charts of MHCII-, CD86-, and CD80-positive cells. The results show that LBP can increase the percentage of mature DCs. In addition, as displayed in Figures 1(e) and 1(f), LBP significantly increases the secretion of IL-6 and IL-4 in DCs except for the LPS group. Our data suggested that LBP can promote DCs phenotype and functional maturity; thus, we next focused on analyzing the molecular mechanism of LBP on DCs.

3.2. LBP Improve TLR4 Expression on the Cell Surface of DCs. Numerous reports show that increased expression of TLRs is one of the immunomodulatory mechanisms of plant polysaccharides played. Therefore, we further detected the expression of TLR4 on DCs after LBP-treated by Taqman-PCR and Western blot. As indicated in Figure 2, a high expression of TLR4 mRNA (Figure 2(a)) and protein (Figure 2(b)) was observed in DCs after stimulation for $30 \mathrm{~min}$ with both LPS and LBP. Furthermore, LBP also showed an increase of TLR4 mRNA and protein level in a dose-dependent manner. Our results suggested that TLR4 plays a pivotal role in regulating the LBP-treated DCs.

3.3. LBP Increase MAPK, Blimp1 $m R N A$, and Protein Expression in DCs. Considering that LBP could induce TLR4 activation on DCs, to study molecular mechanisms whether LBP affect DCs via MAPK and Blimp1 involvement and to determine MAPK and Blimp1 expression in DCs, DCs were cultured with LBP; Taqman-PCR and Western blot were performed to check the mRNA expression of p38 (Figure 3(a)), Erk1 (Figure 3(b)), Erk2 (Figure 3(c)), JNK 


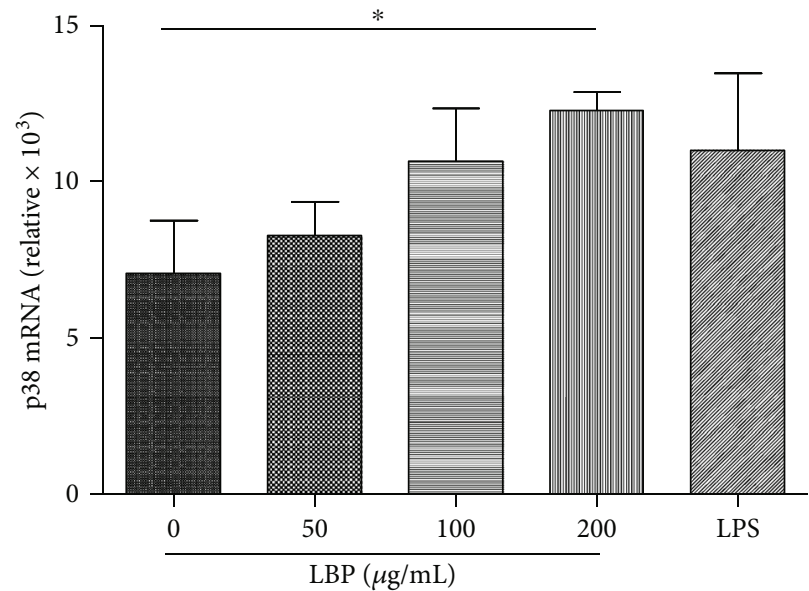

(a)

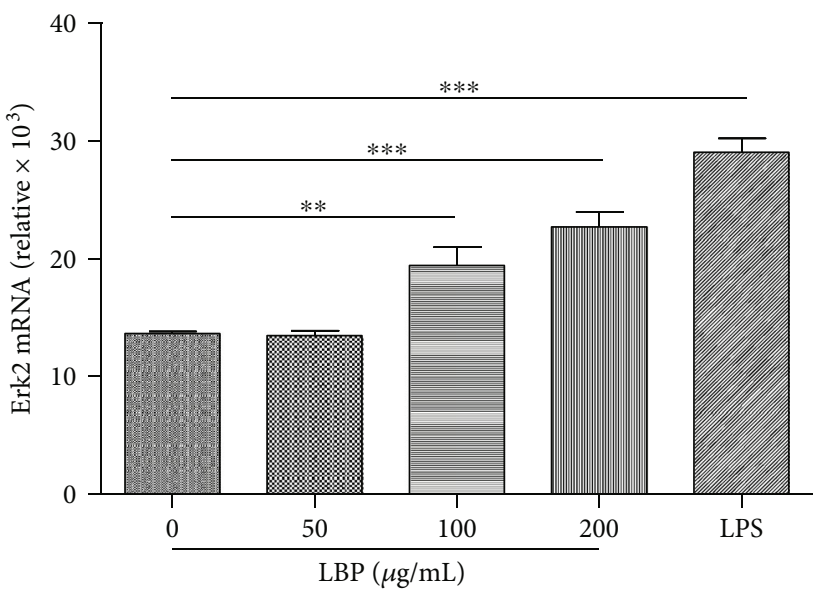

(c)

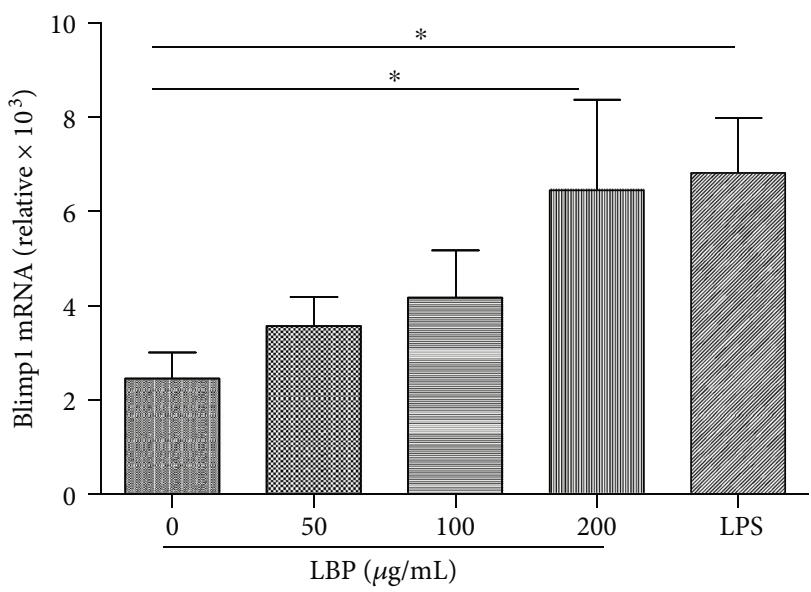

(e)

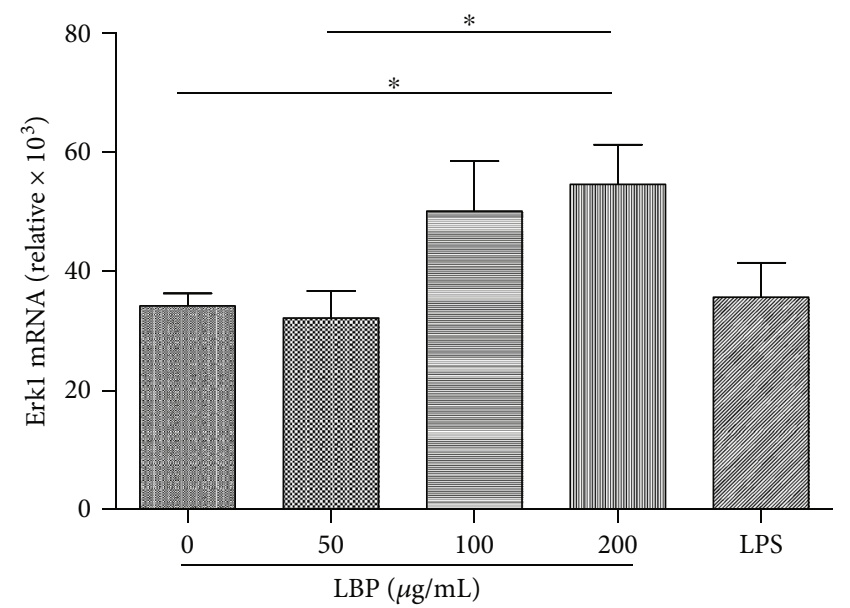

(b)

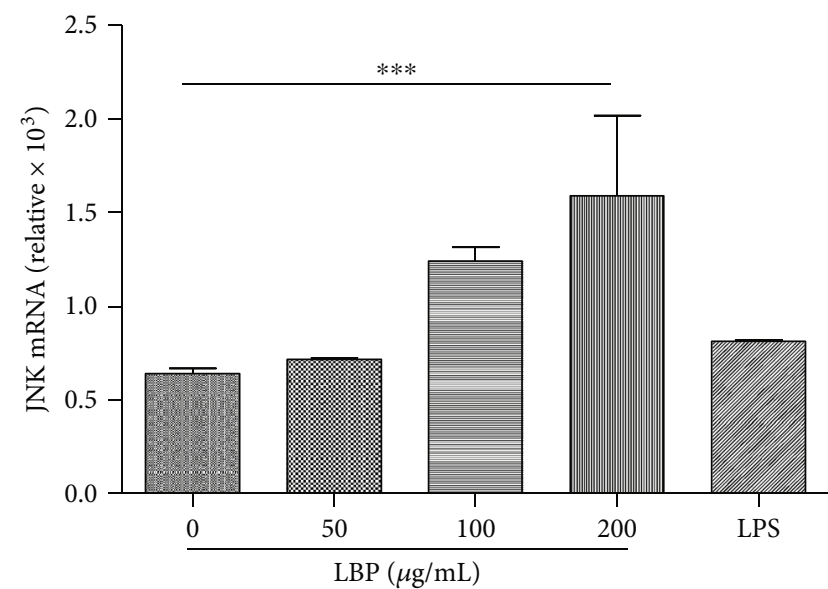

(d)

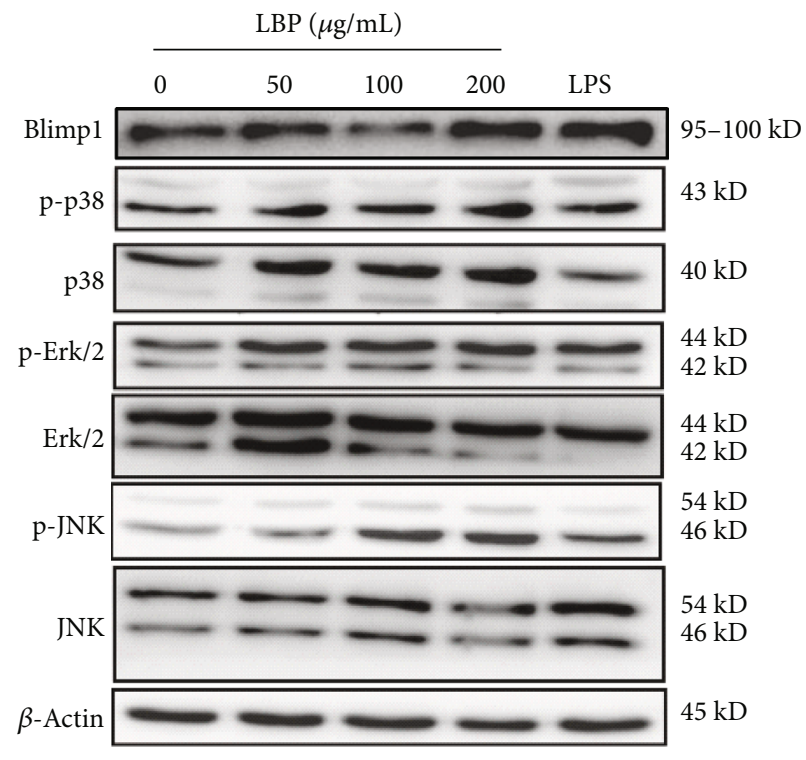

(f)

FIgUre 3: Continued. 


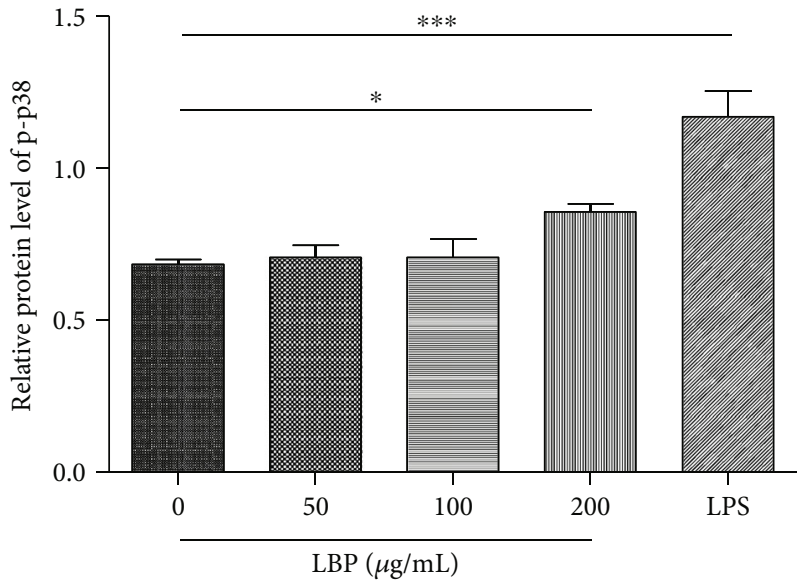

(g)

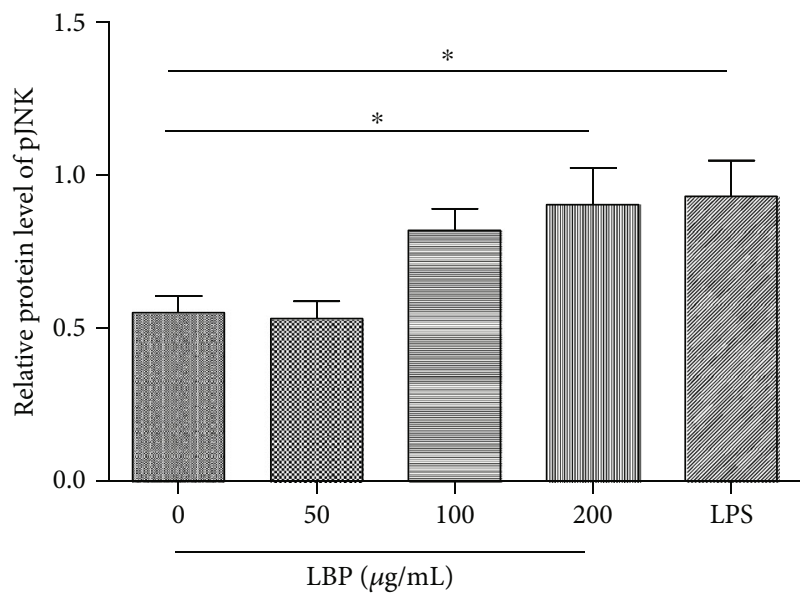

(i)

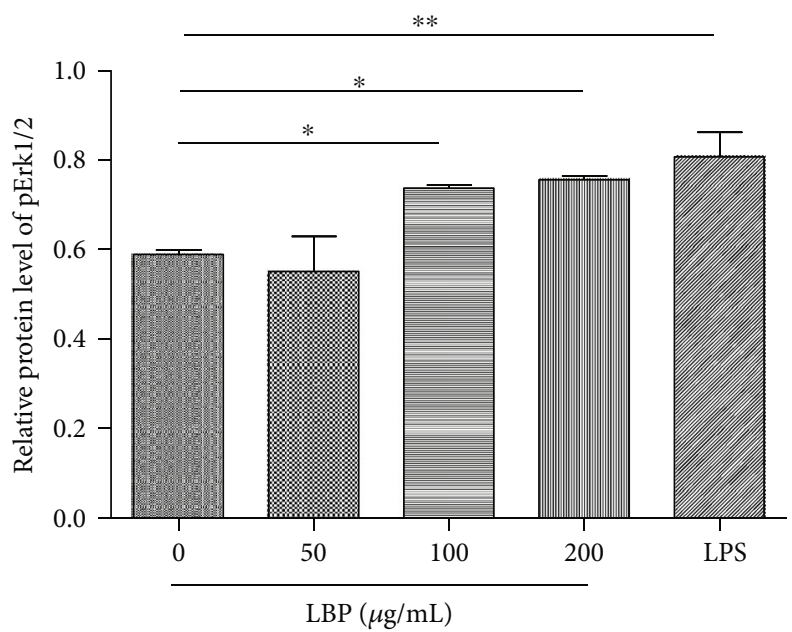

(h)

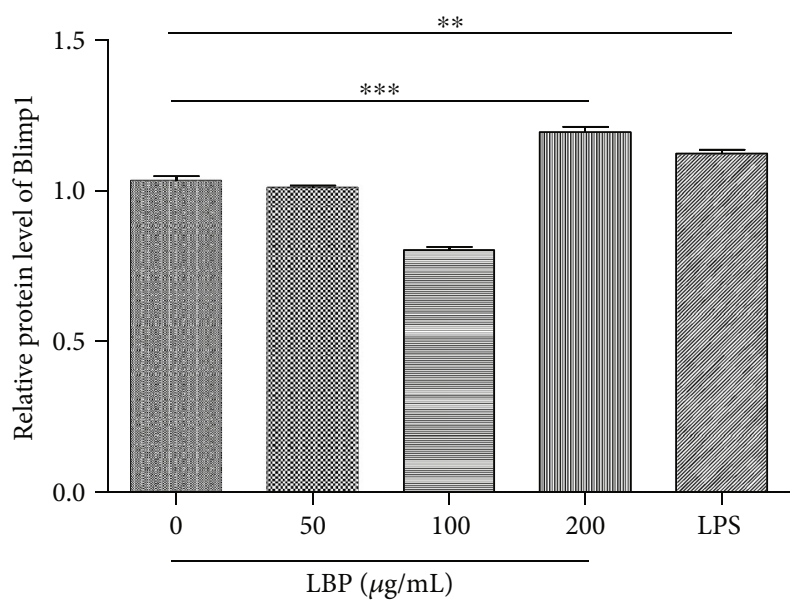

(j)

FIgURe 3: LBP increase MAPK, Blimp1 mRNA, and protein expression in DCs. DCs were stimulated for 30 min with LBP (0, 50, 100, and $200 \mu \mathrm{g} / \mathrm{mL}$ ) and LPS (100 ng/mL), respectively. After stimulation, the mRNA and protein expressions were checked as p38 (a), Erk1 (b), Erk2 (c), JNK (d), Blimp1 (e), p38 (g), Erk1/2 (h), JNK (i), and Blimp1 (j). Values are the mean and SD of 3 independent experiments. ${ }^{*} P<0.05,{ }^{* *} P<0.01$, and ${ }^{* * *} P<0.001$ versus control.

(Figure 3(d)), Blimp1 (Figure 3(e)), phospho-p38 (Figure 3(g)), phospho-Erk1/2 (Figure 3(h)), phosphoMAPK/JNK (Figure 3(i)), and Blimp1 (Figure 3(j)). We found that mRNA and protein expression of these molecules was significantly increased, respectively, after stimulation with LBP $(200 \mu \mathrm{g} / \mathrm{mL})$ for $30 \mathrm{~min}$. These results indicate that LBP can regulate the expression of TLR4 downstream molecules p38, Erk1/2, JNK, and Blimp1 in DCs.

3.4. TAK 242 Reduces TLR4, Erk1/2, Blimp1 mRNA, and Protein Expression in LBP-Induced DCs. To further verify whether LBP regulate DCs via TLR4-MAPK-Blimp1, we preadministered TAK 242 , to specifically inhibit the TLR4 on DCs. Results showed that compared with the RPMI-1640, TAK 242 markedly suppressed LBP-mediated upregulation of TLR4 (Figures 4(a) and 4(h)), Erk1 (Figures 4(b) and 4(i)), Erk2 (Figures 4(c) and 4(i)), and Blimp1 (Figures 4(f) and 4(l)) mRNA and protein expression. However, TAK 242 showed no effect on p38 (Figures 4(d) and 4(j)) or JNK
(Figures 4(e) and 4(k)) mRNA and protein levels. These results suggested that LBP may regulate Blimp1 in DCs though TLR4-Erk1/2.

3.5. MAPK Inhibitors Reduce the $m R N A$ and Protein Expression of MAPK in LBP-Induced DCs. To investigate the TLR4-MAPK-Blimp1 signaling pathway which LBP activates in DCs, we pretreated DCs with the Erk1/2 inhibitor PD98059, which attenuated the induction of Erk1, Erk2 mRNA, and Erk1/2 phosphorylation by LBP in DCs (Figures 5(a), 5(b), and 5(e)), indicating that Blimp1 activation by LBP occurred via canonical TLR4-Erk1/2 activation. Interestingly, when we used SB203580, which is a p38 inhibitor, to pretreat DCs, the pretreated DCs expressed less Blimp1 phosphorylation than untreated cells under either LBP or LPS stimulation (Figures 5(g)-5(i)). Correspondingly, the JNK inhibitor, SP600125, also reduces Blimp1 expression in DCs. Taken together, these results demonstrated that in the presence of LBP, TLR4-Erk1/2-Blimp1 

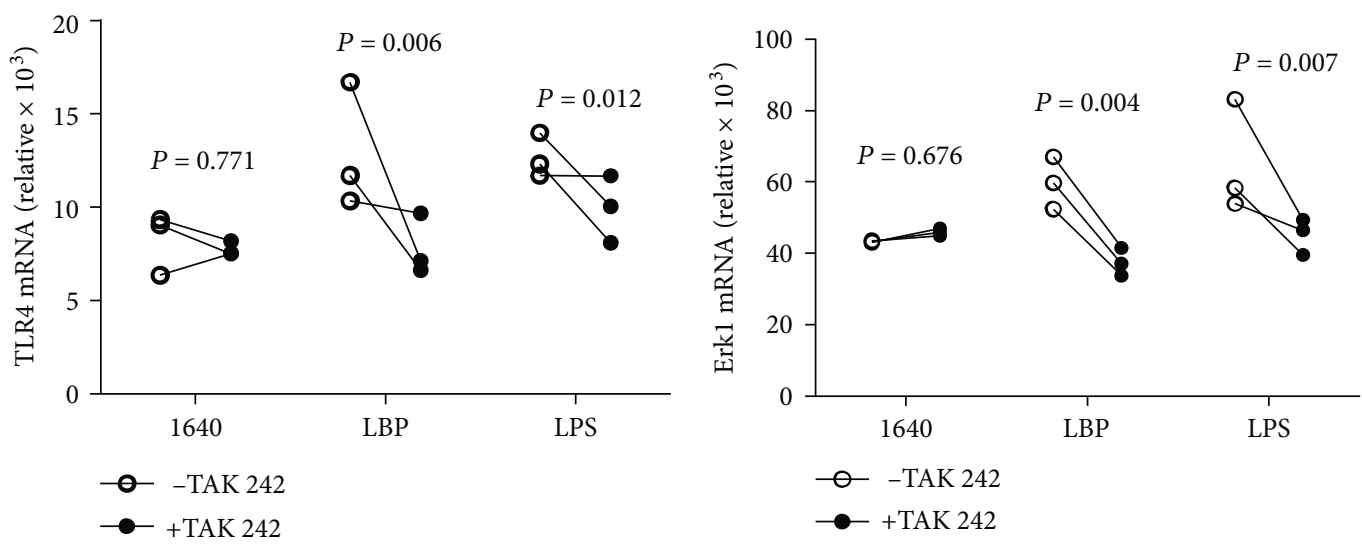

(a)

(b)
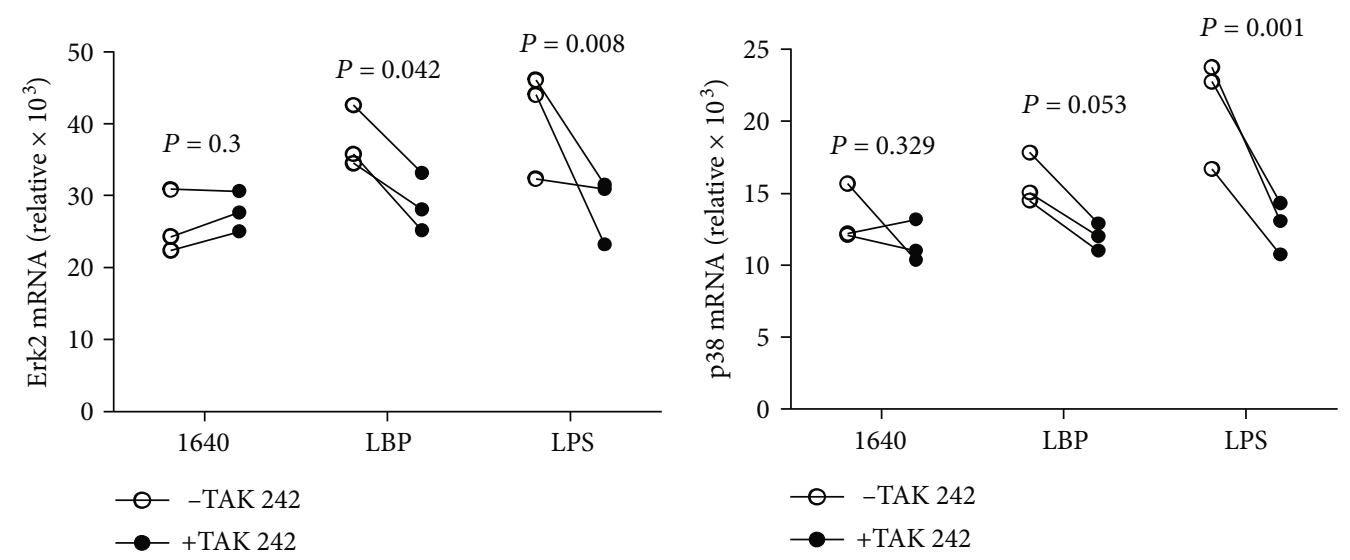

(c)

(d)
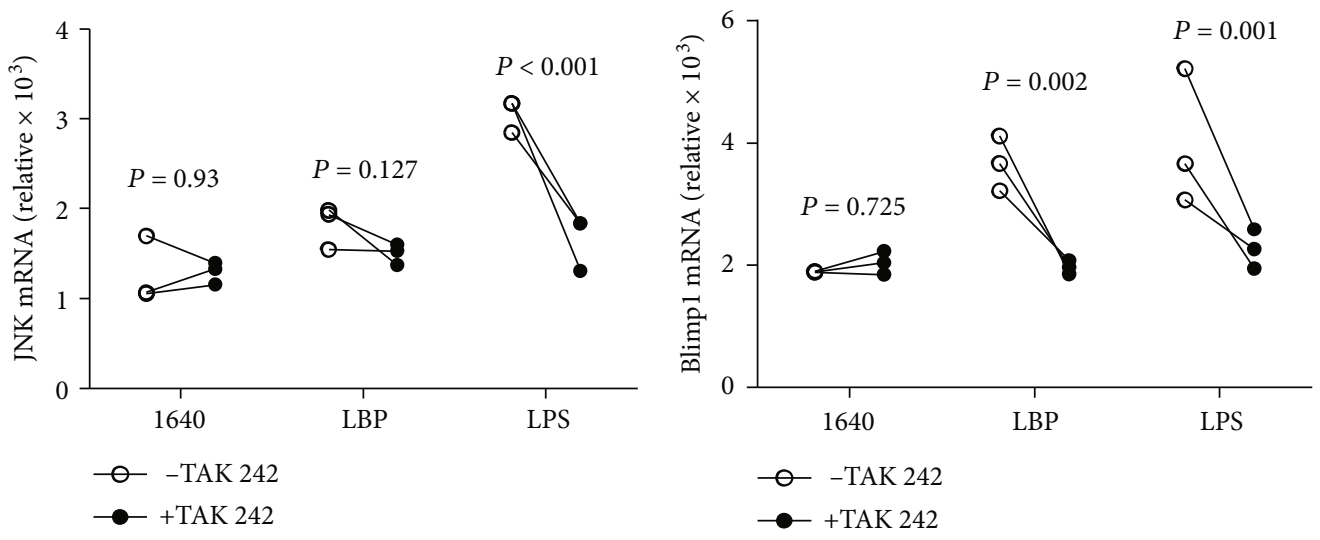

(e)

(f)

Figure 4: Continued. 

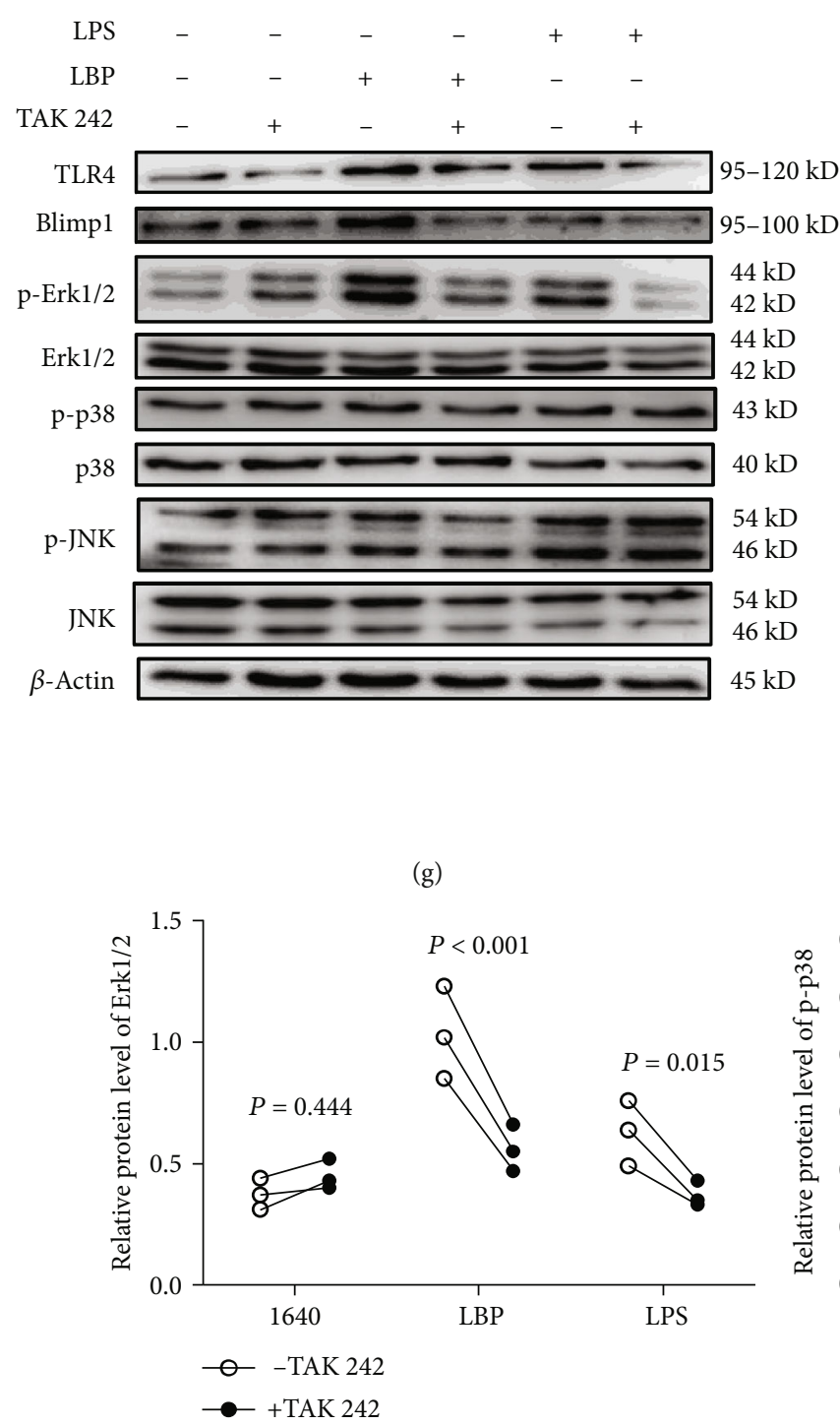

(i)

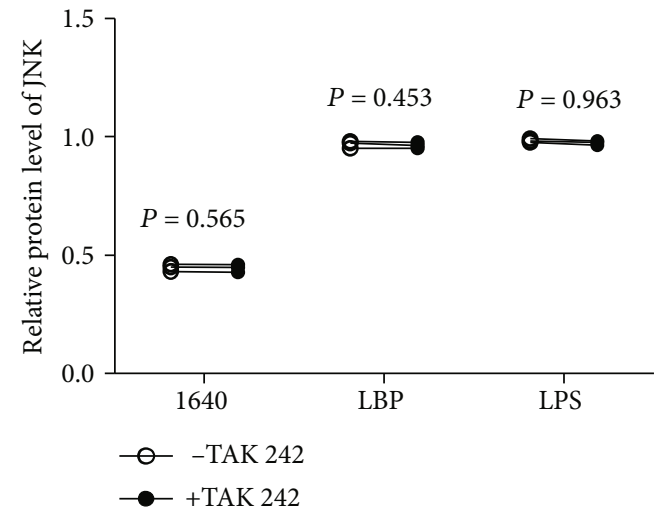

(k)

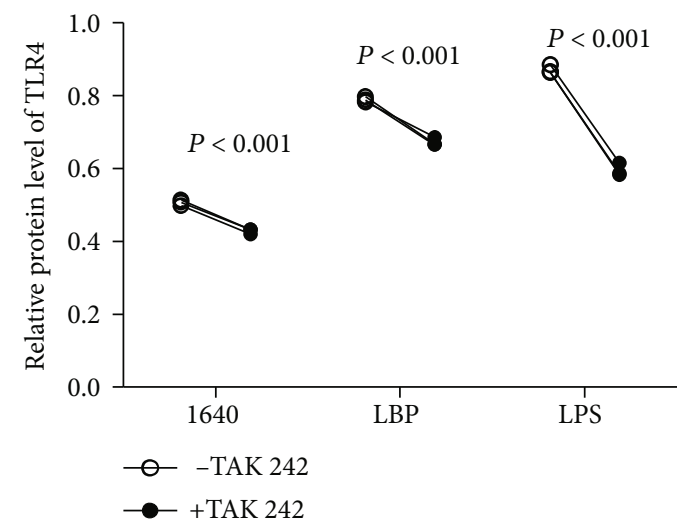

(h)

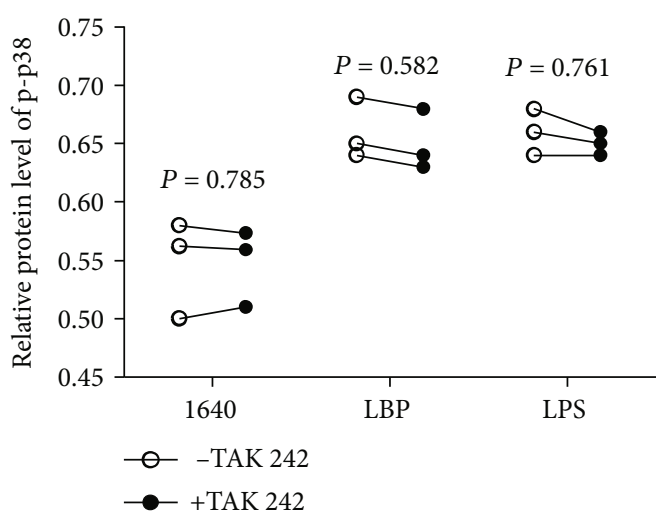

(j)

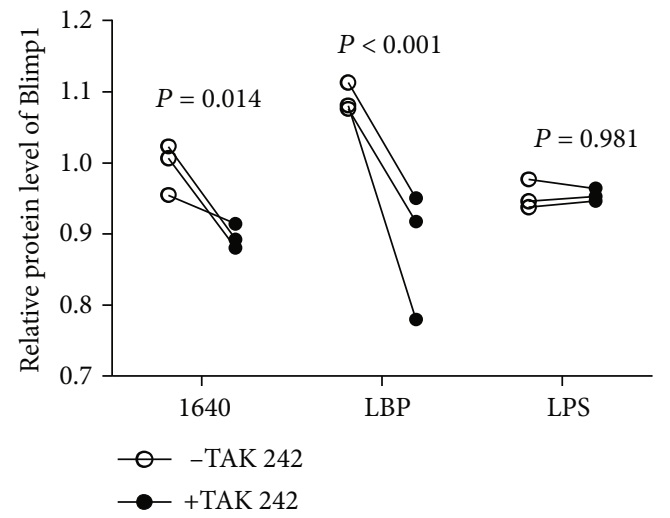

(1)

FIgURE 4: LBP regulate DCs maturation via TLR4-MAPK. DCs were pretreated with TAK $242(10 \mu \mathrm{M})$ for $1 \mathrm{~h}$ and then cocultivated with LPS $(100 \mathrm{ng} / \mathrm{mL})$ or LBP $(200 \mu \mathrm{g} / \mathrm{mL})$ for $30 \mathrm{~min}$. The mRNA and protein expression of TLR4 associated molecules was checked by Taqman-PCR and Western blot as TLR4 ( $\mathrm{a}$ and g), Erk1 (b and h), Erk2 (c and i), p38 (d and j), JNK (e and k), and Blimp1 (f and l). Values are the mean and SD of 3 independent experiments. For the above figures, here, ${ }^{*} P<0.05,{ }^{* *} P<0.01$, and ${ }^{* * *} P<0.001$ were considered statistically significant different from control. 


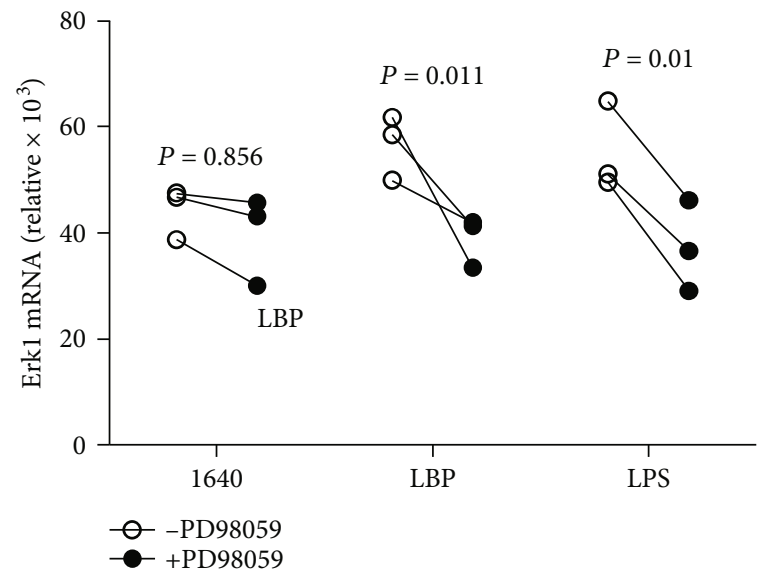

(a)

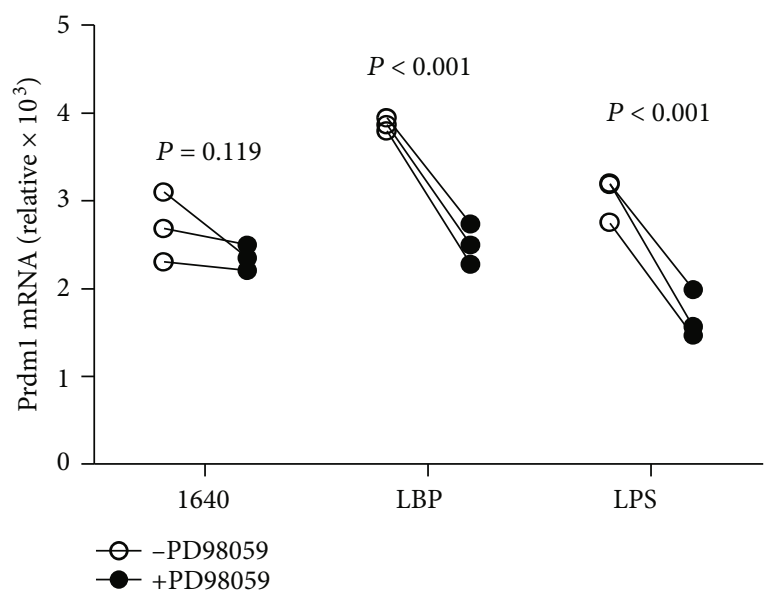

(c)

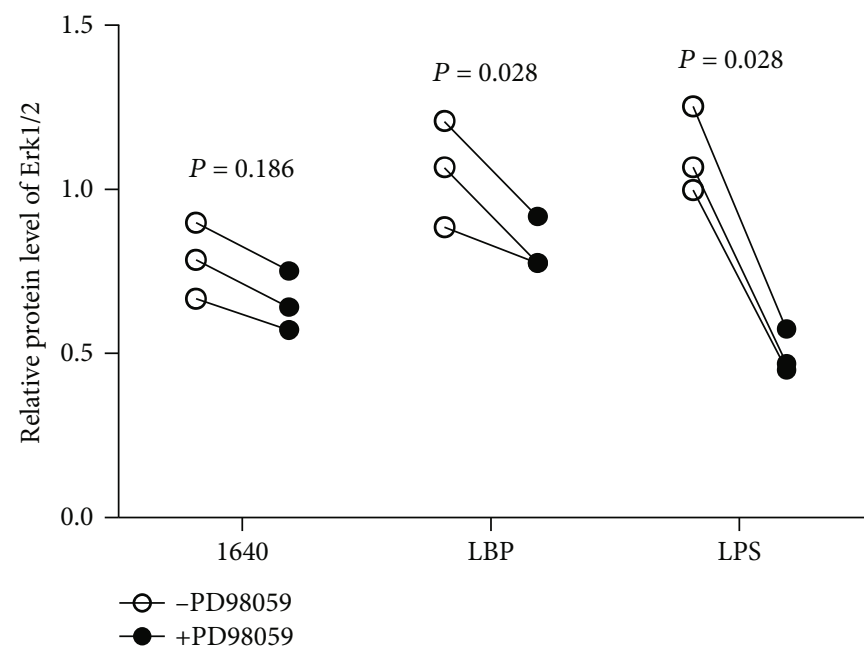

(e)

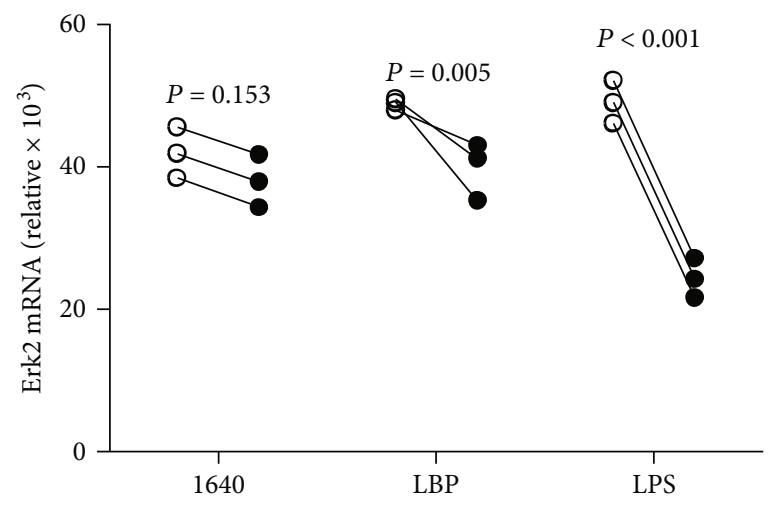

- - -PD98059

(b)

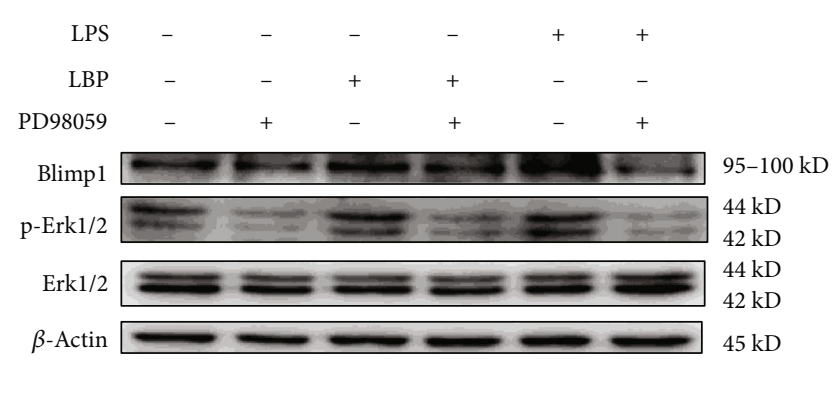

(d)

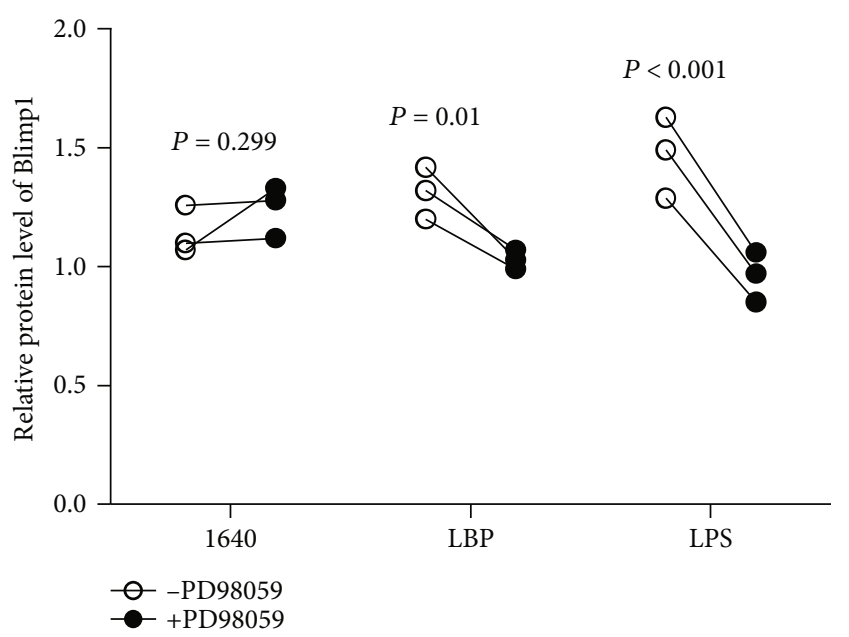

(f)

Figure 5: Continued. 


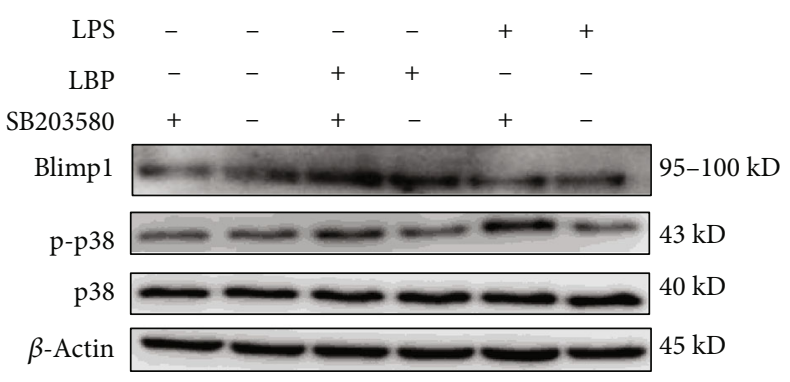

(g)

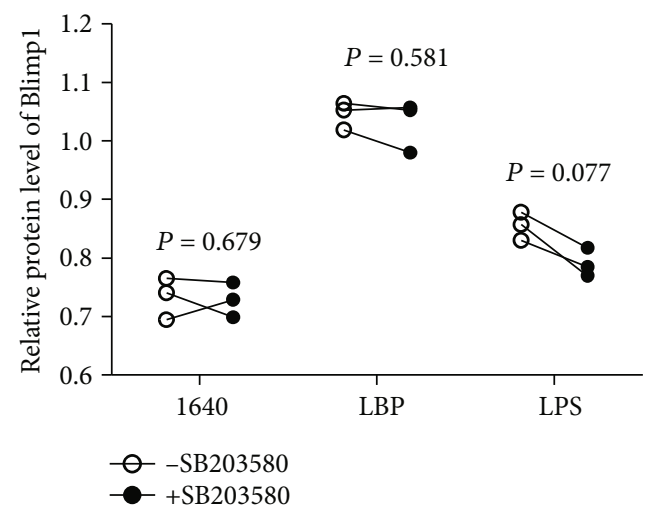

(i)

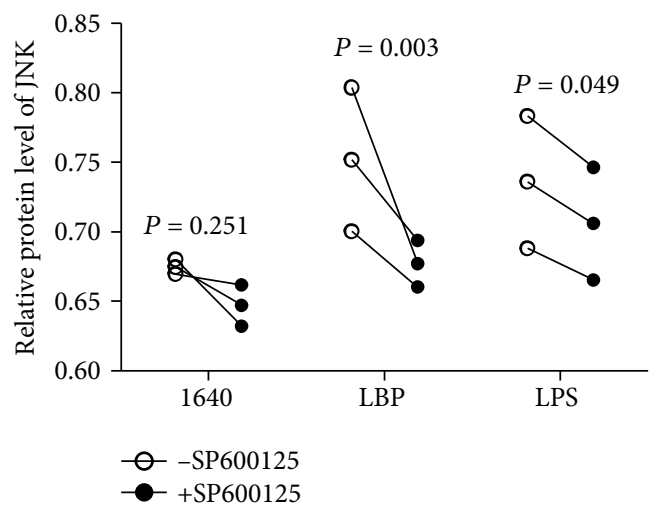

$(\mathrm{k})$

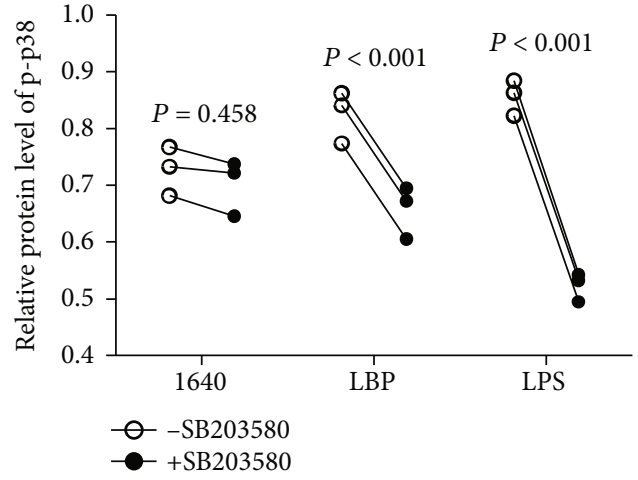

(h)

$$
\begin{array}{rrrrrrr}
\text { LPS } & - & - & - & - & + & + \\
\text { LBP } & - & - & + & + & - & - \\
\text { SP600125 } & - & + & - & + & - & +
\end{array}
$$

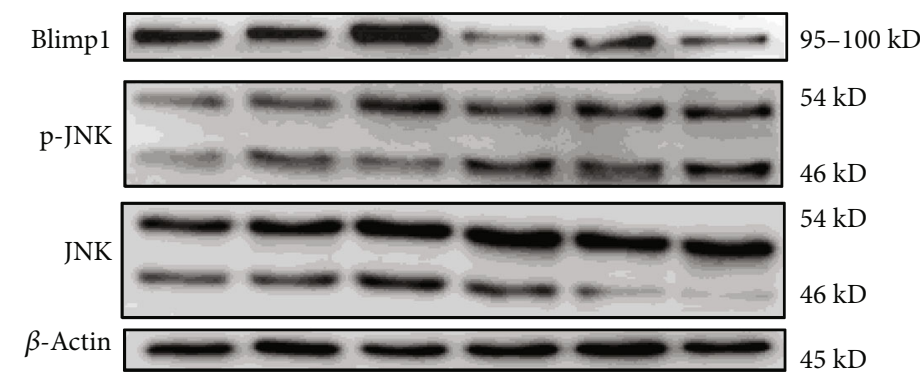

(j)

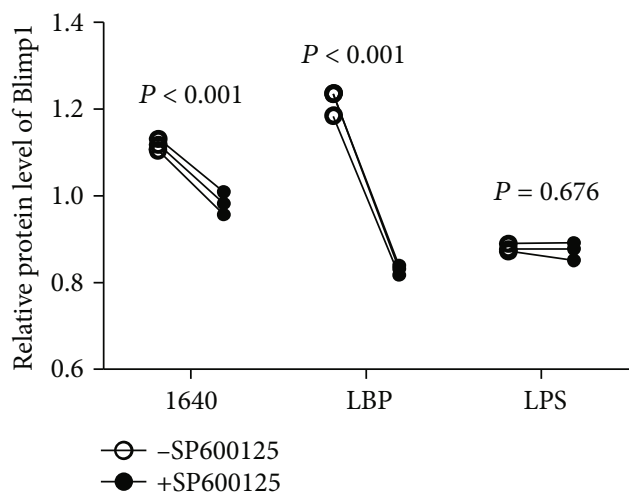

(l)

Figure 5: LBP regulate DCs via TLR4-MAPK-Blimp1. DCs were pretreated with $10 \mu \mathrm{M}$ PD98059, $5 \mu \mathrm{M}$ SB203580, and 50 $\mu \mathrm{M}$ SP600125 for $1 \mathrm{~h}$, respectively, and then treated with $100 \mathrm{ng} / \mathrm{mL}$ LPS or $200 \mu \mathrm{g} / \mathrm{mL}$ LBP for $30 \mathrm{~min}$. The mRNA and protein expression of Erk1/2 (a, b, and e), Blimp1 (c and f), p38 (h), Blimp1 (i), JNK (k), and Blimp1 (l) was analyzed by Taqman-PCR and Western blot. Values are the mean and SD of 3 independent experiments. ${ }^{*} P<0.05,{ }^{* *} P<0.01$, and ${ }^{* * *} P<0.001$.

was drastically activated, whereas p38/JNK-Blimp1 pathway may be activated through another TLR.

3.6. Interference Efficiency of Prdm1 siRNA in DCs. To further analyze the function of Blimp1 in DCs, we took advantage of Prdm1 siRNA to downregulate Blimp1-specifific gene expression in DCs cultured with LBP. The expression of
Blimp1 protein levels in DCs were analyzed by Western blot (Figures 6(a) and 6(b)). Following pulsing with LBP, Blimp1 protein levels in DCs were markedly increased compared with those of nonpulsed DCs (Figure 6(b)). The levels of Blimp1 protein in DCs transfected with siRNA-Prdm1-3 or siRNA-Prdm1-4 were decreased around 50\% compared with DCs transfected with siRNA-NC or mock-treated DCs 


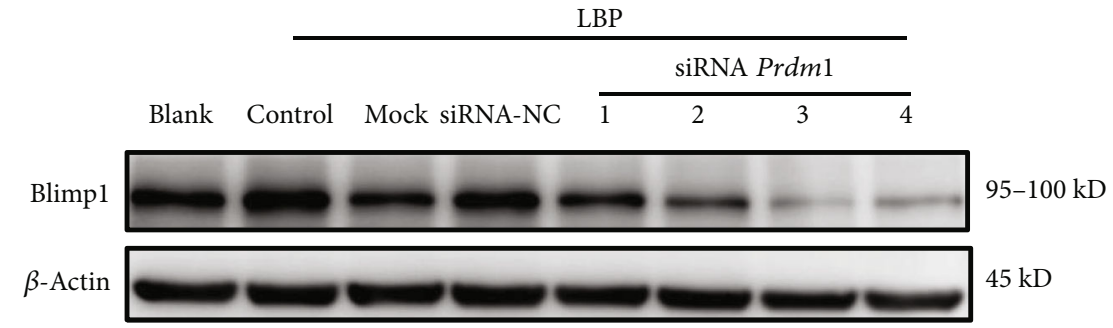

(a)

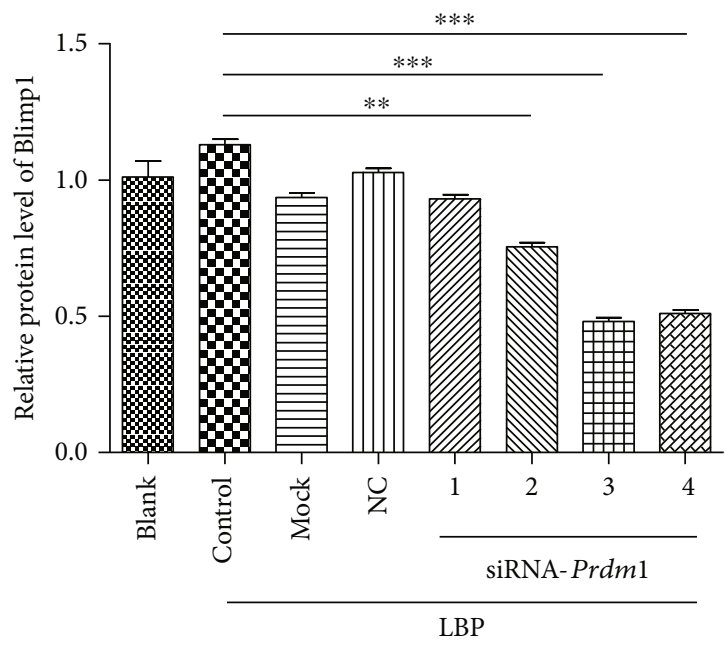

(b)

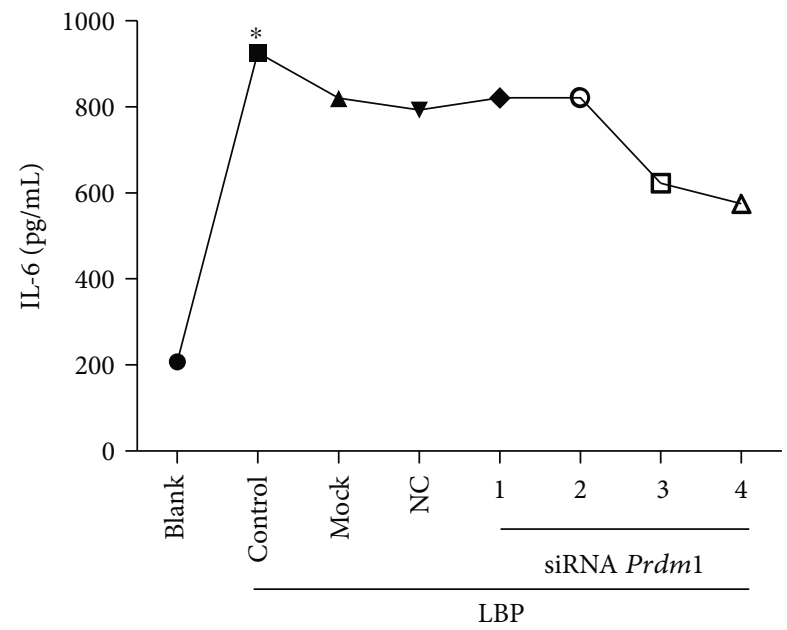

(c)

Figure 6: Gene silencing in LBP induced DCs using Blimp1-specific siRNA. DCs were transfected with siRNA-Prdm1-1, siRNA-Prdm1-2, siRNA-Prdm1-3, siRNA-Prdm1-4, siRNA-NC, reagent alone (mock-treated), or nontransfected cells (control). After coculture of transfected DCs with LBP for $24 \mathrm{~h}$, the expression of Blimp1 was detected by Western blot ( $\mathrm{a}$ and $\mathrm{b}$ ), and the IL- 6 concentration in the culture supernatant was detected by ELISA (c). $\beta$-Actin expression was treated as internal reference. Values are the mean and SD of 3 independent experiments. ${ }^{*} P<0.05,{ }^{* *} P<0.01$, and ${ }^{* * *} P<0.001$ versus control.

(Figure 6(b)). In addition, as displayed in Figure 6(c), the content of IL- 6 in the cell culture supernatant added with siRNA-Prdm1-3 or siRNA-Prdm1-4 showed a downward trend. These results suggested that the $\operatorname{Prdm} 1$ gene is silenced in immature DCs, the maturation of DCs will be inhibited, and the IL- 6 concentration in the culture supernatant will be reduced.

3.7. LBP Increase TLR4, Erk1/2, and Blimp1 Expression In Vivo. To confirm whether LBP induces TLR4, Erk1/2, and Blimp1 expression in vivo, we injected mice intraperitoneally with LBP for 7 consecutive days. CD11c magnetic beads were used to sort DCs from the spleen cell suspension. CD11c cells were detected with flow cytometry after sorting, and the efficiency of sorting is about $70 \%$. Then, the whole cell protein was extracted. We found the protein expression of TLR4 (Figure 7(b)), Erk1/2 (Figure 7(c)), and Blimp1 (Figure $7(\mathrm{~d})$ ) was significantly increased compared to the PBS group.

\section{Discussion}

DC is the body's main antigen-presenting cell and plays a key role in controlling and activating immune responses [26].
During immune response, mature DCs have stronger antigen-presenting ability than immature DCs. LPS, CpG, poly I:C, or TNF- $\alpha$ in some ways was used as an inducer of DC maturation, but their application range is limited due to toxic side effects [27]. Numerous studies have demonstrated that plant polysaccharides can also effectively induce the maturation of DCs, including Ganoderma lucidum polysaccharides, astragalus, Cordyceps sinensis, and LBP $[2,5,28,29]$.

As a well-known Chinese medicine, LBP has been considered a nourishing food content for thousands of years, and its immune regulation effects are played by its bioactive substances [30-33]. Previous studies have shown that Lycium barbarum polysaccharide liposome (LBPL) can activate immature DCs and induce DC maturation characterized by upregulation of cell surface molecules MHCII, CD80, CD86, and CD40, production of cytokines IL-12p40 and TNF- $\alpha$, and enhancement of antigen presentation $[34,35]$. In our research, we verified that LBP can induce DC maturation, which was upregulation of $\mathrm{CD} 11 \mathrm{c}^{+-}$

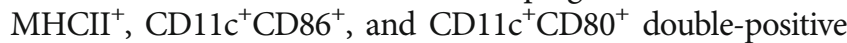
DCs (Figures 1(a)-1(c)) and induction of IL-6 (Figure 1(e)) and IL-4 (Figure 1(f)) production from DCs. Our results indicate that LBP $(200 \mu \mathrm{g} / \mathrm{mL})$ can promote the expression level of DC maturation markers (Figure 1). Mature DCs were capable of secreting a variety of cytokines, mainly IL-6 and IL-4. 


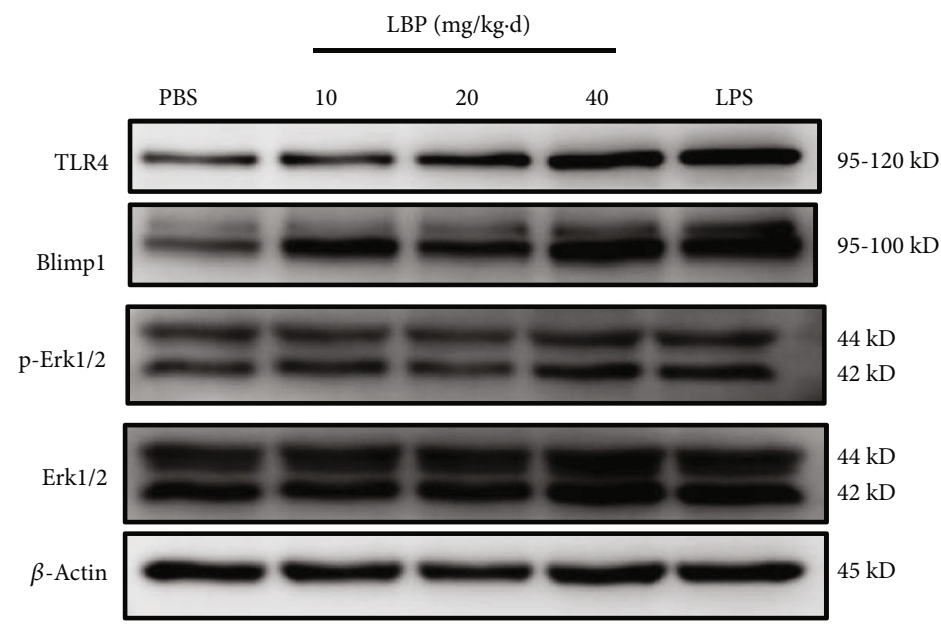

(a)

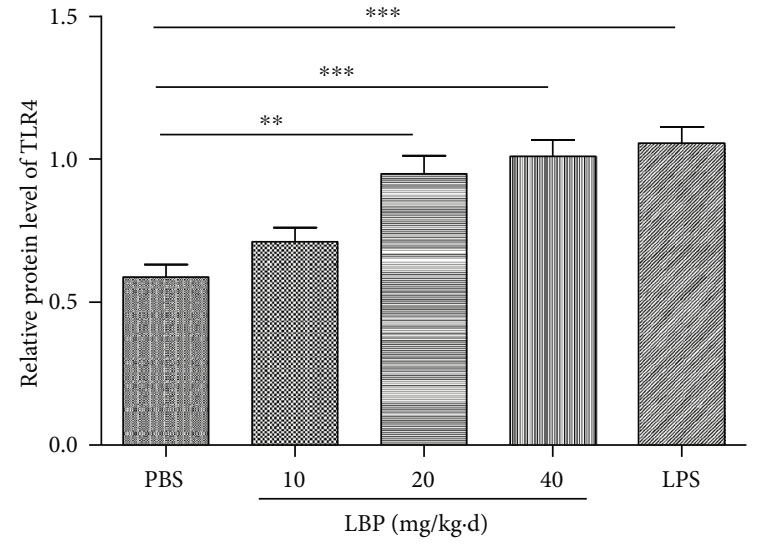

(b)

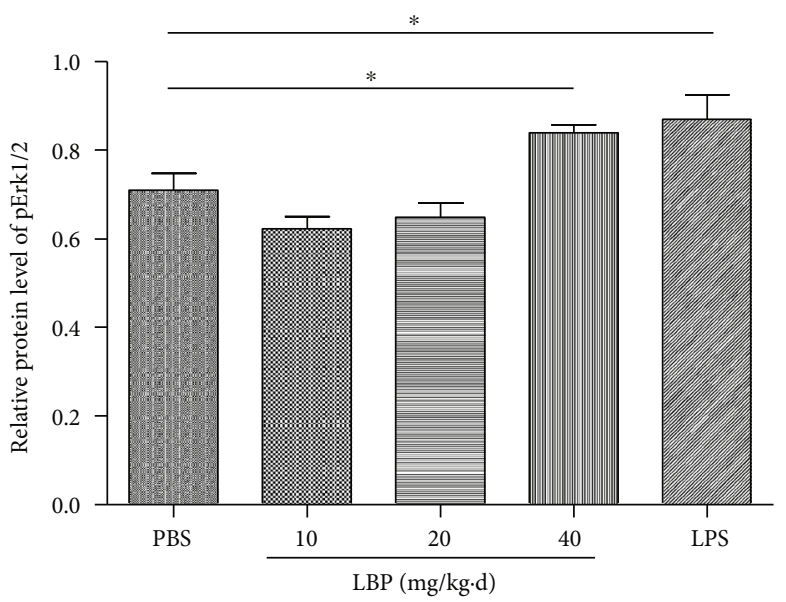

(c)

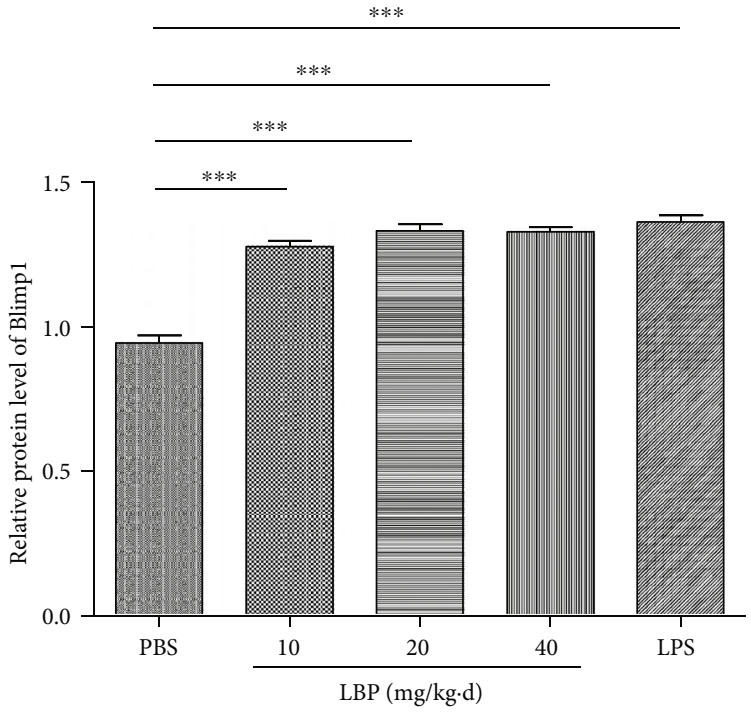

(d)

Figure 7: LBP induces the expression of TLR4, Erk1/2, and Blimp1 in DCs from a mouse spleen in vivo study. Both LBP (0, 10, 20, and $40 \mathrm{mg} / \mathrm{kg}$ ) and LPS (1 mg/kg) were administered intraperitoneally to C57BL/6 mice in three groups. After 7 days, mouse splenic DCs were isolated and examined for TLR4 (b), Erk1/2 (c), and Blimp1 (d) expression by Western blot. Values are the mean and SD of 5 independent experiments. ${ }^{*} P<0.05$, and ${ }^{* *} P<0.01$, and ${ }^{* * *} P<0.001$ versus control. 
TLRs are classic cell surface proteins that play an important role in identifying invading pathogens while activating immune cells to produce cytokines [24]. The stimulation of TLRs leads to the activation of several transcription factors, including MAPK. Dziarski, the first scholar, reported that LPS can induce the activation of MAPK signaling pathways in macrophages, such as Erk1/2, p38, and MAPK/JNK [36]. Zhang et al. demonstrated that LBPF4-OL can significantly enhance p38 phosphorylation and inhibit JNK and Erk1/2 MAPK phosphorylation in LPS-induced macrophages [37]. However, it is not fully understood whether the MAPK signaling pathway is involved in DC activation by LBP.

Various roles of Blimp1 in B and $\mathrm{T}$ cell differentiation and development have been reported, but little is known about the act of Blimp1 in DCs differentiation and maturation [38]. In recent years, Chan and his collaborators found that Blimp1 is induced following maturation of DCs cultured with GM-CSF [39]. However, the molecular mechanism by which Blimp1 activates DCs still remains elusive. Therefore, we are interested to explore whether Blimp1 is involved in the downstream signaling molecules of TLR4-Erk1/2 in LBP-regulated DCs in this study.

Our studies showed that $200 \mu \mathrm{g} / \mathrm{mL}$ of LBP significantly induced the mRNA and phosphorylated protein expression of TLR4, p38, Erk1/2, JNK, and Blimp1 in DCs compared with RPMI-1640 stimulation. After treatment of DCs with the TLR4 inhibitor (TAK 242), mRNA and protein expression of LBP-induced TLR4, Erk1/2, and Blimp1 was significantly downregulated. At the same time, we used the Erk1/2 inhibitor (PD98059) to treat DCs; we found that the mRNA and protein expression of LBP-induced Erk1/2 and Blimp1 was inhibited. More interestingly, TAK 242 had no significant effect on the expression of $\mathrm{p} 38$ and JNK proteins; however, the level of Blimp1 protein was decreased after the treatment of SB203580 and SP98059.

PRDM1, which encodes Blimp1, plays an indispensable role in the differentiation and development of a variety of cells [17]. After silencing Prdm1 in DCs, we were surprised to find that there was a downward trend in IL-6 secretion by DCs, considering that the maturation of DCs might be impaired due to knockdown of Blimp1, and thus, IL-6 secretion was reduced. In summary, LBP regulated the maturation of DCs via the TLR4-Erk1/2-Blimp1-dependent pathway and promoted IL-6 production (Supplementary Graphical Abstract).

\section{Conclusion}

We verified that LBP were capable of inducing the maturation of DCs by increasing MHCII, CD80, and CD86 expression. Additionally, we found that LBP could enhance the mRNA and protein expression of TLR4, p38, Erk1/2, JNK, and Blimp1 during DC maturation. More importantly, we found that LBP can promote maturity of murine DCs through the TLR4-Erk1/2-Blimp1 signaling pathway.

\section{Data Availability}

The data used to support the findings of this study are available from the corresponding author upon reasonable request.

\section{Conflicts of Interest}

The authors declare no conflict of interest.

\section{Authors' Contributions}

Xiangguo Duan and Yaru Lan contributed equally to this work.

\section{Acknowledgments}

This work was supported by the National Natural Science Foundation of China (No. 31860695, No. 81760437, and No. 81560466), Ningxia High School First-Class Disciplines (West China First-Class Disciplines Basic Medical Sciences at Ningxia Medical University, NXYLXK2017B07), and Research and Development Plan of the 13th Five-year Plan of Ningxia Autonomous Region (award number 2016BZ02).

\section{Supplementary Materials}

LBP mediates the maturation of murine DCs through the TLR4 pathway. LBP regulated the maturation of DCs via the TLR4-Erk1/2-Blimp1-dependent pathway and promoted IL-6 production. These signaling pathways may provide a novel evidence for understanding the molecular mechanisms of LBP on activating murine DCs. (Supplementary Materials)

\section{References}

[1] H. Amagase, B. Sunand, and C. Borek, "Lycium barbarum (goji) juice improves in vivo antioxidant biomarkers in serum of healthy adults," Nutrition Research, vol. 29, no. 1, pp. 19-25, 2009.

[2] Z. Chen, J. Lu, N. Srinivasan, B. K. H. Tan, and S. H. Chan, "Polysaccharide-protein complex from Lycium barbarum L. is a novel stimulus of dendritic cell immunogenicity," Journal of Immunology, vol. 182, no. 6, pp. 3503-3509, 2009.

[3] M. Jin, Q. Huang, K. Zhao, and P. Shang, "Biological activities and potential health benefit effects of polysaccharides isolated from Lycium barbarum L," International Journal of Biological Macromolecules, vol. 54, pp. 16-23, 2013.

[4] S.-F. Zhou, J. Cheng, Z.-W. Zhou et al., “An evidence-based update on the pharmacological activities and possible molecular targets of Lycium barbarum polysaccharides," Drug Design, Development and Therapy, vol. 9, pp. 33-78, 2014.

[5] J. Zhu, Y. Zhang, Y. Shen, H. Zhou, and X. Yu, "Lycium barbarum polysaccharides induce Toll-like receptor 2- and 4mediated phenotypic and functional maturation of murine dendritic cells via activation of NF- $\kappa \mathrm{B}$," Molecular Medicine Reports, vol. 8, no. 4, pp. 1216-1220, 2013.

[6] J. Banchereau, F. Briere, C. Caux et al., "Immunobiology of dendritic cells," Annual Review of Immunology, vol. 18, no. 1, pp. 767-811, 2000.

[7] N. S. Wilson and J. A. Villadangos, "Regulation of antigen presentation and cross-presentation in the dendritic cell network: facts, hypothesis, and immunological implications," Advances in Immunology, vol. 86, pp. 241-305, 2005.

[8] Y. L. Chen, T. T. Chen, L. M. Pai, J. Wesoly, H. A. R. Bluyssen, and C. K. Lee, "A type I IFN-Flt3 ligand axis augments plasmacytoid dendritic cell development from common lymphoid 
progenitors," The Journal of Experimental Medicine, vol. 210, no. 12 , pp. 2515-2522, 2013.

[9] A. H. Lichtman, "T cell costimulatory and coinhibitory pathways in vascular inflammatory diseases," Frontiers in Physiology, vol. 3, p. 18, 2012.

[10] Y. S. Choi, D. Eto, J. A. Yang, C. Lao, and S. Crotty, "Cutting edge: STAT1 is required for IL-6-mediated Bcl6 induction for early follicular helper cell differentiation," Journal of Immunology, vol. 190, no. 7, pp. 3049-3053, 2013.

[11] D. Eto, C. Lao, D. DiToro et al., "IL-21 and IL-6 are critical for different aspects of B cell immunity and redundantly induce optimal follicular helper CD4 T cell (Tfh) differentiation," PLoS One, vol. 6, no. 3, p. e17739, 2011.

[12] R. I. Nurieva, Y. Chung, G. J. Martinez et al., "Bcl6 mediates the development of $\mathrm{T}$ follicular helper cells," Science, vol. 325, no. 5943, pp. 1001-1005, 2009.

[13] J. A. Harker, G. M. Lewis, L. Mack, and E. I. Zuniga, "Late interleukin-6 escalates $\mathrm{T}$ follicular helper cell responses and controls a chronic viral infection," Science, vol. 334, no. 6057, pp. 825-829, 2011.

[14] A. Ballesteros-Tato, B. León, B. A. Graf et al., "Interleukin-2 inhibits germinal center formation by limiting $\mathrm{T}$ follicular helper cell differentiation," Immunity, vol. 36, no. 5, pp. 847-856, 2012.

[15] R. J. Johnston, A. C. Poholek, D. DiToro et al., "Bcl6 and Blimp-1 are reciprocal and antagonistic regulators of $\mathrm{T}$ follicular helper cell differentiation," Science, vol. 325, no. 5943, pp. 1006-1010, 2009.

[16] D. Yu, S. Rao, L. M. Tsai et al., "The transcriptional repressor Bcl-6 directs $\mathrm{T}$ follicular helper cell lineage commitment," Immunity, vol. 31, no. 3, pp. 457-468, 2009.

[17] G. Martins and K. Calame, "Regulation and functions of Blimp-1 in T and B lymphocytes," Annual Review of Immunology, vol. 26, no. 1, pp. 133-169, 2008.

[18] D. Savitskyand and K. Calame, "B-1 B lymphocytes require Blimp-1 for immunoglobulin secretion," The Journal of Experimental Medicine, vol. 203, no. 10, pp. 2305-2314, 2006.

[19] D. E. Schliephake and A. Schimpl, "Blimp-1 overcomes the block in IgM secretion in lipopolysaccharide / anti- $\mu \mathrm{F}\left(\mathrm{ab}^{\prime}\right.$ )-co-stimulated B lymphocytes," European Journal of Immunology, vol. 26, no. 1, pp. 268-271, 1996.

[20] S. J. Kim, Y. R. Zou, J. Goldstein, B. Reizis, and B. Diamond, “Tolerogenic function of Blimp-1 in dendritic cells," The Journal of Experimental Medicine, vol. 208, no. 11, pp. 2193-2199, 2011.

[21] H. Yang, Q. Qiu, B. Gao, S. Kong, Z. Lin, and D. Fang, "Hrd1mediated BLIMP-1 ubiquitination promotes dendritic cell MHCII expression for CD4 T cell priming during inflammation," The Journal of Experimental Medicine, vol. 211, no. 12, pp. 24672479, 2014.

[22] S. J. Kim, P. K. Gregersen, and B. Diamond, "Regulation of dendritic cell activation by microRNA let-7c and BLIMP1," The Journal of Clinical Investigation, vol. 123, no. 2, pp. 823-833, 2013.

[23] I. Ando, Y. Tsukumo, T. Wakabayashi et al., "Safflower polysaccharides activate the transcription factor NF- $\kappa \mathrm{B}$ via Tolllike receptor 4 and induce cytokine production by macrophages," Int Immunopharmacol, vol. 2, no. 8, pp. 1155-1162, 2002.

[24] X. R. Zhang, C. H. Qi, J. P. Cheng et al., "Lycium barbarum polysaccharide LBPF4-OL may be a new Toll-like receptor 4/MD2-MAPK signaling pathway activator and inducer," International Immunopharmacology, vol. 19, no. 1, pp. 132141, 2014.
[25] S. Zhang, S. Nie, D. Huang, W. Li, and M. Xie, "Immunomodulatory effect of Ganoderma atrum polysaccharide on CT26 tumor-bearing mice," Food Chemistry, vol. 136, no. 3-4, pp. 1213-1219, 2013.

[26] R. M. Steinman, "Decisions about dendritic cells: past, present, and future," Annual Review of Immunology, vol. 30, no. 1, pp. 1-22, 2012.

[27] W. T. Chang, T. H. Lai, Y. J. Chyan et al., "Specific medicinal plant polysaccharides effectively enhance the potency of a DC-based vaccine against mouse mammary tumor metastasis," PLoS One, vol. 10, no. 3, p. e0122374, 2015.

[28] J. Du, X. Chen, and C. W. H. Sun, "Pathway analysis of global gene expression change in dendritic cells induced by the polysaccharide from the roots of Actinidia eriantha," J Ethnopharmacol, vol. 214, pp. 141-152, 2018.

[29] N. Zhu, X. Lv, Y. Wang et al., "Comparison of immunoregulatory effects of polysaccharides from three natural herbs and cellular uptake in dendritic cells," International Journal of Biological Macromolecules, vol. 93, no. Part A, pp. 940-951, 2016.

[30] X. Pengand and G. Tian, "Structural characterization of the glycan part of glycoconjugate LbGp2 from Lycium barbarum L," Carbohydrate Research, vol. 331, no. 1, pp. 95-99, 2001.

[31] L. Gan, S. H. Zhang, Q. Liu, and H. B. Xu, "A polysaccharideprotein complex from Lycium barbarum upregulates cytokine expression in human peripheral blood mononuclear cells," European Journal of Pharmacology, vol. 471, no. 3, pp. 217-222, 2003.

[32] L. Gan, S. Hua Zhang, X. Liang Yang, and H. Bi Xu, "Immunomodulation and antitumor activity by a polysaccharideprotein complex from Lycium barbarum," International Immunopharmacology, vol. 4, no. 4, pp. 563-569, 2004.

[33] G. Du and L. L. J. Fang, "Experimental study on the enhancement of murine splenic lymphocyte proliferation byLycium barbarum glycopeptide," Journal of Huazhong University of Science and Technology [Medical Sciences], vol. 24, no. 5, pp. 518-520, 2004.

[34] R. Bo, Y. Sun, S. Zhou et al., "Simple nanoliposomes encapsulating $<\mathrm{em}>$ Lycium barbarum $</ \mathrm{em}>$ polysaccharides as adjuvants improve humoral and cellular immunity in mice," International Journal of Nanomedicine, vol. 12, pp. 62896301, 2017.

[35] R. Bo, Z. Liu, J. Zhang et al., "Mechanism of Lycium barbarum polysaccharides liposomes on activating murine dendritic cells," Carbohydrate Polymers, vol. 205, pp. 540-549, 2019.

[36] J. Y. Liu, F. L. Yang, C. P. Lu et al., "Polysaccharides fromDioscorea batatasInduce tumor necrosis factor- $\alpha$ secretion via Tolllike receptor 4-mediated protein kinase signaling pathways," Journal of Agricultural and Food Chemistry, vol. 56, no. 21, pp. 9892-9898, 2008.

[37] R. Dziarski, Y. P. Jinand, and D. Gupta, "Differential activation of extracellular signal-regulated kinase (ERK) 1, ERK2, p38, and c-Jun NH2-terminal kinase mitogen-activated protein kinases by bacterial peptidoglycan," The Journal of Infectious Diseases, vol. 174, no. 4, pp. 777-785, 1996.

[38] A. D. Keller and T. Maniatis, "Identification and characterization of a novel repressor of beta-interferon gene expression," Genes \& Development, vol. 5, no. 5, pp. 868-879, 1991.

[39] Y. H. Chan, M. F. Chiang, Y. C. Tsai et al., "Absence of the transcriptional repressor Blimp-1 in hematopoietic lineages reveals its role in dendritic cell homeostatic development and function," Journal of Immunology, vol. 183, no. 11, pp. 70397046, 2009. 